\title{
METALLOGRAPHIC ETCHING REAGENTS. III: FOR ALLOY STEELS
}

\author{
By Edward C. Groesbeck
}

ABSTRACT

There has been lacking in the existing literature a rationale which would guide one in making an intelligent selection of a suitable etching reagent for identifying, by means of metallographic etching reagents, the constituents present in various alloy steels, ferro-alloys, and special alloys. This investigation was undertaken to find such a rationale for alloy steels and ferro-alloys containing chromium, tungsten, and vanadium.

Experimental data on the etching behavior of typical constituents found present in these steels and ferro-alloys and in ligh-speed steels toward various alkaline solutions under oxidizing and nonoxidizing conditions were obtained, using the simple immersion and electrolytic etching methods.

The principles governing this behavior were determined from these data and results of tests made with certain solntions. Briefly stated, they are based on (1) two distinct effects obtained with alkaline etching solutions in the immersion method, (a) a chemical attack of the constituent by the alkali, and (b) the oxidation of the constituent by nascent oxygen formed in the solution; and (2) similar effects by electrolytic etching witl solutions of weakly dissociated acids, both alkaline and metallic salts of these acids, and alkalis, although the nascent oxygen is derived from different sources, $(a)$ a secondary reaction between the acid formed in the first stages of the electrolysis and water, and (b) by discharge of hydroxyl ions on the anode (specimen). A differentiation of the various constituents is thus made possible.

A quite complete, though brief, review of the literature on equilibrium diagrams of the alloy systems and on constituents found in alloy steels and ferroalloys is included.

\section{CONTENTS}

I. Introduction

II. Aim of investigation

III. Equilibrium diagrams of binary and ternary systems in alloy stecls

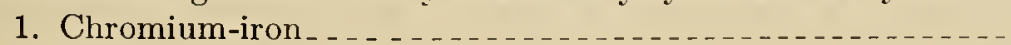

2. Chromium-carbon

3. Cliromium-iron-carbon $\ldots \ldots \ldots \ldots$

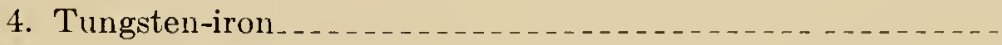

5. Tungsten-carbon _.............

6. Tungsten-iron-carbon

7. Vanadium-iron_... $\ldots \ldots \ldots \ldots \ldots$

8. Vanadium-iron-carbon $\ldots \ldots \ldots$

9. Molybdenum-iron _.......... 535

10. Molybdenum-iron-carbon _... 536 
IV. Nature of constituents present in alloy stcels and ferro-alloys

1. Chromium steels._._._.

2. Chromiun-tungsten steels $\ldots \ldots \ldots \ldots$

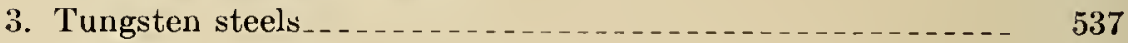

4. Vanadium steels $\ldots \ldots \ldots 58$

5. Molybdenum steels_.

6. High-speed steels $\ldots$

V. Materials and methods $\ldots \ldots \ldots$

VI. Experimental results

1. Etching by immersion 544

(a) Preliminary tests . .

(b) Tests in neutral and alkaline solutions with and witl-

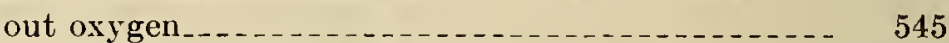

1. Sodium or potassium hydroxide solution_._. $\quad 547$

2. Sodium picrate solution _._. 549

3. Potassium ferricyanide solution _._.

4. Potassium permanganate solution _. $\ldots \ldots \ldots 53$

5. Potassium-copper cyanide solution _ _ _._. 554

6. Recapitulation_... 55

2. Electrolytic etching tests

3. Heat-tinting tests

4. Micrographic illustrations of etching effects produced _... 566

VII. Summary and conclusions _...

VIII. Selected bibliography _._.

\section{INTRODUCTION}

In the literature there appears to be no well-established rationalo to which etching reagents recommended by various investigators for the identification of certain constituents in plain carbon and alloy steels may show a clearly defined relationship. Many of these etcling reagents eridently owe their development to the special needs engendered by the circumstances surrounding the case in question. It would appear that the development of these rarious reagents was unrelated to any general scheme, although considerations of a chemical nature necessarily entered into each particular case.

The use of reagents of an acidic nature for dereloping the microstructure of alloy steels appears to be the general practice, particularly when not more than one structurally free constituent is assumed to be present. High-speed steels may be cited as an example. It might appear that all the undarkened particles obserred in the microstructure of such steels, as brought out by etching with an acid reagent, were of the same nature, as judged from the fact that apparently all these particles were darkened br the sodium hyrlroxide and hydrogen peroxide etching reagent dereloped by Yatseritch (68).1 It would seem that no consideration had been made of the possibility of the existence of rery small particles of another constituent which

\footnotetext{
${ }_{1}$ The figures inclosed in parentheses here and throughout the text relate to the numbered referenees in the selected bibliography given at the end of this paper.
} 
would behave differently toward Yatsevitch's reagent and because of their size be not readily noticed in the unetched matrix. The need of directing greater attention to other methods of developing the mierostructure of alloy steels thus suggests itself, if more reliable knowledge of the details revealed in the microsection is to be sought.

Where there is present in the microstructure more than one structurally free constituent-for example, iron carbide and another constituent attributable to the alloying element-etching with an acidic reagent will fail to distinguish between the two unless differences in their structural characteristics permit identification. On the other hand, such a reagent is useful and convenient for revealing the general distribution and arrangement of the structurally free constituents.

The present knowledge regarding the true nature of several of the constitutents found in alloy steels is still far from being eomplete; this subject is discussed at greater length in Seetion IV. A reliable determination of the chemical composition of a constitutent which has been separated from an alloy steel by chemical means-for example, by the aid of eleetrolysis-is obviously beset with serious difficulties because of the relatively minute size of the particles coupled with the danger of their incomplete separation from the surrounding matrix or other compounds mechanically mixed therewith or of contamination of the carbide residues by the solution formed in the separating process. The recent advances in X-ray analysis, however, hold out some hopes of a successful method of attacking this problem by this means, as indieated by the work of Bain and Jeffries (11) and of Westgren and Phragmén (65). Since an incomplete knowledge regarding these constitutents still exists, no attempt has been made in this paper to indicate the nature of the constituent under consideration further than by a general designation, such as chromium carbide, etc.

The general methods employed in metallographic etching practice are as follows: (a) Simple immersion, in which the prepared surface or "microsection" is exposed by immersion to the action of the etching solution; (b) electrolytic etching, where a weak electric current is used in conjunction with a suitable electrolyte and the specimen to be etched is made one of the terminals, usually the anode, of the "cell"; $(c)$ heat tinting, which is essentially a heating of the specimen to such a temperature that an oxide film forms and a differential eoloring of the eonstitutents is produced.

\section{AIM OF INVESTIGATION}

In addition to collecting experimental data on the behavior toward various etching reagents of the constituents, which are likely to oceur in common alloy steels, this work was undertaken with the endeavor to find a rationale by which one could be guided in the 
etching procedure for the identification of one or more constituents that may be present in alloy steels or special alloys, as ferro-alloys, etc., or in developing new etching reagents to meet new cases as they arise. The work was confined to the constituents found in the more common alloy steels as chromium, tungsten, vanadium, and highspeed steels. Molybdenum is generally assumed to have similar characteristics to tungsten, and no efforts were made to obtain samples of molybdenum steels containing free carbicle particles.

\section{EQUILIBRIUM DIAGRAMS OF BINARY AND TERNARY SYSTEMS IN ALLOY STEELS}

As an aid to predicting the existence of compounds that may be present and identified in the microsection of the alloy steel, a résumé of the existing knowledge, still very incomplete in many instances, regarding the equilibrium diagram of the binary and ternary systems likely to be met with in commercial alloy steels may here be not amiss.

\section{CHROMIUM-IRON}

Fischbeck (19) has recently given a diagram, based on the results of Treitschke and Tammann (62), Jänecke (37), and Monnartz (42), indicating that there are two eutectics-one 15 per cent chromium and $1,410^{\circ} \mathrm{C}$., the other 60 per cent chromium and $1,260^{\circ} \mathrm{C}$ - - present in this system. Murakami (44), however, concluded from his magnetic analyses that these two metals form solid solutions for all proportions.

\section{CHROMIUM-CARBON}

This system was inrestigated by Ruff and Foehr (55) and Murakami (44) simultaneously, though independently. Both concluded from microscopic evidence that a simple eutectic is formed, and that the carbide is soluble at eutectic temperature in chromium to about 0.5 per cent carbon. They differed widely, however, as to the composition of the carbide $\left(\mathrm{Cr}_{5} \mathrm{C}_{2}, 8.45\right.$ per cent carbon, and $\mathrm{Cr}_{4} \mathrm{C}, 5.45$ per cent carbon, respectively) and the carbon content of the eutectic (about 4.3 and 1.7 per cent, respectively).

\section{CHROMIUM-IRON-CARBON}

Although numerous papers on chromium steels, particularly concerning the properties as produced by heat treatment and also the relation of these properties to the composition as well as to the assumed state of the chromium in steel, have appeared during the last 35 years, it is only within the last decade that systematic study was made of the chromium-iron-carbon system. It is true that about 20 years ago Guillet (27) published a diagram, based on the results of microscopic observations on two series of steel containing 
0.2 and 0.8 per cent carbon and different amounts of chromium, which indicated in an approximate manner the microstructures to be expected with rarying percentages of chromium and of carbon.

Murakami (44) published in 1918 the results of a comprehensive study made of this system by means of magnetic and microscopic analysis. He furnished a diagram, somewhat similar to Guillet's, although the boundary lines were more accurately located.

Later Oberhoffer and Daeres $(46,48)$ and Russell $(57)$ determined by the microscopic method the solubility limit for the eutectic in chromium-iron-carbon alloys. Their results, with those of Murakami, are shown in Figure 1. It will be seen that there is, allowing

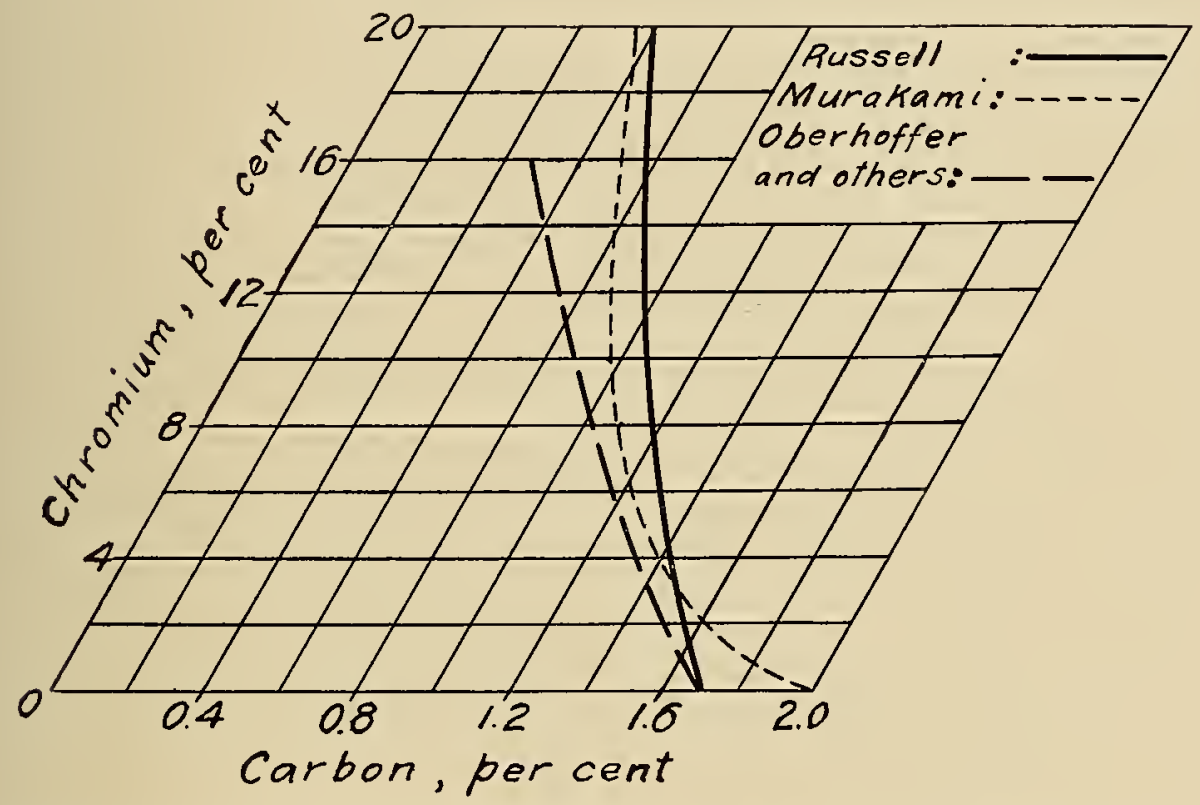

FIG. 1.-Solubility (or saturation) limit for the eutectic in chromium-iron-carbon alloys, as determined by Murakami (4/7), Oberhoffer and Daeves $(46,48)$, and Russell (57).

for the fact that Murakani set the zero chromium point-that is, the point of saturation for cementite in the iron-carbon system-at 2.0 per cent carbon rather at the generally accepted value of 1.7 per cent, fairly good agreement. The eutectic, with any primary carbicle present, should be expected as a structurally free constituent in steels of chromium and carbon contents lying to the right of the solubility curve while those to the left of the curve should show no eutectic. Figure 1 also shows the lowering effect produced by the increase of chromium upon the solubility of cementite in iron-carbon alloys; for example, approximately 14 per cent chromium should lower the solubility limit by about 1 per cent carbon. Goerens and Stadeler (22) have also given data along this line in alloys containing 4 to 5 per cent carbon. Daeves (14) has called attention to the fact 
that the "stepping over" of this solubility curve in the case of chromium steels, as well as tungsten, from left to right produces a decided change in the tensile and other properties because of the presence of the eutectic.

\section{TUNGSTEN-IRON}

This system was studied by Harkort (28), Bornemann (12), who plotted a diagram based on Harkort's results, Ionda and Murakami (31), and Ozawa (50). Ozawa's diagram, a modification of that of Honda and Murakami, is reproduced in part in Figure 2. Honda

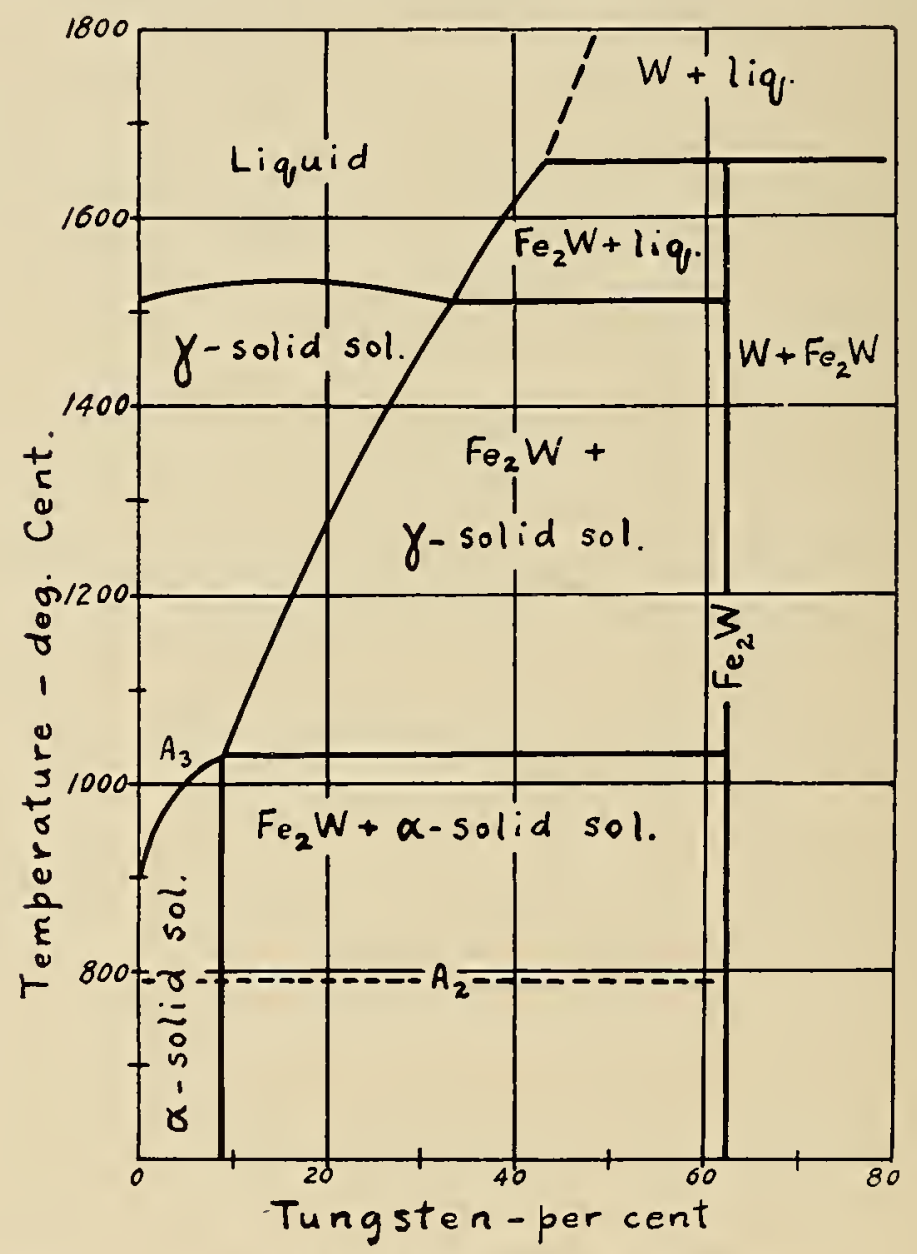

FIG. 2.-Tungsten-iron equilibrium diagram, after Ozawa (50).

and Murakami's conclusion that $\mathrm{Fe}_{2} \mathrm{~W}$ is the only compound of the two metals was confirmed by Ozawa. This diagram will show that for unquenched alloys the solubility of $\mathrm{Fe}_{2} \mathrm{~W}$ in iron extends to 9 per cent tungsten, while in alloys containing from 9 to 33 per cent tungsten $\mathrm{Fe}_{2} \mathrm{~W}$ separates out and is identified in the microstructure as globules of a relatively hard constituent. Alloys with 33 to 62 per cent tungsten show primary crystals of $\mathrm{Fe}_{2} \mathrm{~W}$ in needle form, in 
aldition to the globules of $\mathrm{Fe}_{2} \mathrm{~W}$ which separated from the solid solution as the alloy cooled. In alloys exceeding 62 per cent tungsten particles of metallic tungsten surrounded by an envelope of $\mathrm{Fe}_{2} \mathrm{~W}$ occur.

\section{TUNGSTEN-CARBON}

Ruff and Wunsch (56) appear to be the only investigators who have undertaken anything of a systematic study of this system. They determined, by microscopic observations and chemical analysis, the existence of two carbides of tungsten, tricarbide, $\mathrm{W}_{3} \mathrm{C}$, containing 2.12 per cent carbon, by weight, and monocarbide, WC, containing 6.12 per cent carbon. They also inferred from thermal analysis data as well as microstructure the probable existence of a compound, $\mathrm{W}_{2} \mathrm{C}$, intermediate between $\mathrm{W}_{3} \mathrm{C}$ and $\mathrm{WC}$. $\mathrm{W}_{3} \mathrm{C}$ was reported to be slightly soluble in tungsten, and that three eutectics were found: (a) W: $\mathrm{W}_{3} \mathrm{C}$ at 1.4 per cent carbon and $2,690^{\circ} \mathrm{C}$; (b) metastabile ternary eutectic of $\mathrm{W}_{3} \mathrm{C}, \mathrm{WC}$ and an unidentified carbide $\left(\mathrm{W}_{2} \mathrm{C}\right.$ ?) at about 2.4 per cent carbon and $2,660^{\circ} \mathrm{C}$; ; and $(c) \mathrm{WC}$ : unidentificd carbide $\left(\mathrm{W}_{2} \mathrm{C}\right.$ ? $)$ at 3.5 per cent carbon and $2,580^{\circ} \mathrm{C}$.

In a determination of the electrical conductance at room temperature of tungsten lamp filaments, previously subjected at incandescent tempcratures to a carbonizing process in naphthalene vapor, with the degree of carbonizing attained, Mary R. Andrews (2) found two change points in the conductance curve at 3.16 and 6.12 per cent carbon. Since these values correspond exactly to the carbon content in $\mathrm{W}_{2} \mathrm{C}$ and $\mathrm{WC}$, respectively, she concluded that at these points the filament was completely converted into these two carbides. No results indicating the formation of a carbide corresponding to the formula $\mathrm{W}_{3} \mathrm{C}$ were obtained.

Hultgren (35) reported the presence of a white, hard microscopic constituent in tungsten that had been carburized by welding with a carbon electrode. He concluded that this was probably $\mathrm{W}_{3} \mathrm{C}$, but did not find it in his iron-tungsten-carbon alloys.

\section{TUNGSTEN-IRON-CARBON}

No really satisfactory equilibrium diagram of this system has been constructed, for several reasons: (1) Many of the results of several investigators are contradictory; (2) not a very large amount of data, particularly thermal, has been obtained; and (3) the true nature of some of the constituents already found has not been established.

Honda and Murakami (31) were the first, in a study by magnetic analysis and microscopic observations of tungsten steels and the changes produced by heat treatment, to publish, in 1918, a diagram indicating what zones, with respect to the tungsten and carbon con- 
tent, should show in the microstructure such constituents as iron tungstide, cementite, tungsten carbide, and double carbide of iron and tungsten.

Later, 1920, Hultgren (35) summarized the results of an extensive microscopical and thermal study of tungsten steels and related alloys. Although realizing the incompleteness of his data, he furnished a tentative diagram, which differs markedly from that of Honda and Murakami, mainly in the fact that the former diagram is based on equilibrium at high temperatures (gamma iron), while the latter represents conditions at room temperatures (alpha iron). Only a small part of Hultgren's diagram is based on his experimental data, the rest is largely conjectured, though based on considerations of known facts.

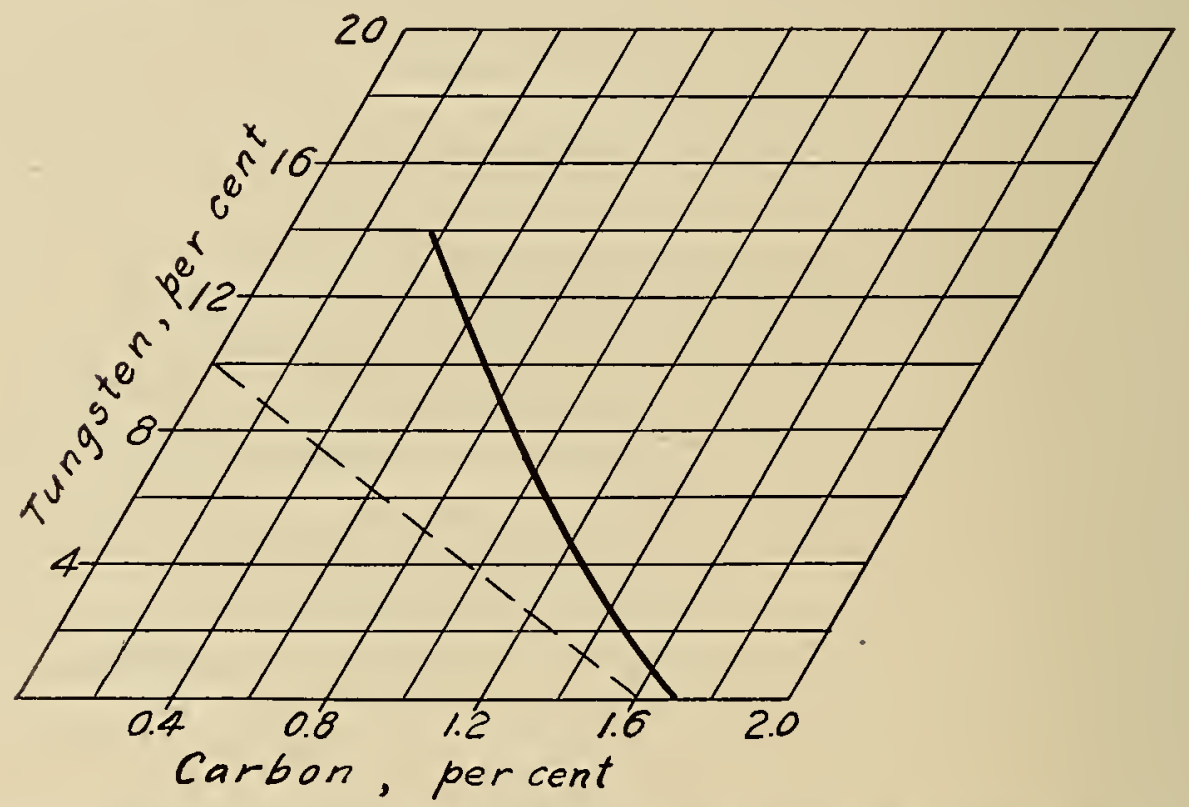

FIG. 3.-Solubility (or saturation) limit for the eutectic in tungsten-iron-carbon alloys, as determined by Oberhoffer and Daeves $(46,48)$, full line, and Guillet (26), broken line

Ozawa (50), 1922, published a triangular constitutional diagram. plotted from data obtained in his magnetic and thermal analyses and microscopic observations. He reported the ternary eutectic point, 15 per cent tungsten, 3.6 per cent carbon, and 81.4 per cent iron, $1,065^{\circ} \mathrm{C}$. He advanced the statement that cementite and iron tungstide are mutually soluble within each other up to a certain concentration and form a binary eutectic, and that in steels having high tungsten and carbon content the separation from the solid solution of angular-shaped crystals of tungsten carbide (WC) occurs when they are heated for a sufficiently long time at high temperature.

Figure 3 shows the solubility line for this system, which Oberhoffer and Daeves $(46,48)$ determined. Alloys having compositions to the 
right of this line should show in the microstructure an eutectic, those to the left should show none. Ozawa shows in his diagram a similar curve. The fine broken line in this figure is that given by Guillet (26) in his diagram as separating the cementitic tungsten steels from the pearlitic steels.

\section{VANADIUM-IRON}

Vogel and Tammann (63) published an equilibrium diagram, showing that vanadium and iron form solid solutions in all proportions. They stated that these alloys have a homogeneous microstructure. Norris (45) has stated that in vanadium steels the ferrite retains in solid solution a few hundredths of 1 per cent of vanadium. Giesen (20) reported, several years before, this quantity as being approximately 0.6 per cent.

\section{VANADIUM-IRON-CARBON}

No equilibrium diagram for this system has, as far as is known, been published. Considerable work has, howerer, been done on the effect of vanadium in carbon steels and alloy steels, particularly with respect to heat treatment and mechanical properties. Some conclusions reached by several investigators would show that vanadium has apparently a greater affinity for carbon than iron, and that a special constituent thus formed increases in quantity with the vanadium content, whereas the amount of iron carbide decreases till only vanadium carbide remains. Arnold and Read (6) concluded from the results of microscopic examination and of chemical analyses of carbide residues from a series of vanadium steels that the amount of vanadium required to absorb all of the carbon present in steels of approximately eutectoid composition exceeds 5 per cent, the formula of the vanadium carbide being $\mathrm{V}_{4} \mathrm{C}_{3}$. They also concluded that no double carbide of iron and vanadium is formed.

\section{MOLYBDENUM-IRON}

Guertler (25) gives an equilibrium diagram showing that molybdenum forms a solid solution with iron, and that within the 30 to 80 per cent molybdenum range a compound $\left(\mathrm{Fe}_{3} \mathrm{Mo}_{2}\right.$ ?) occurs in the iron-molybdenum solution. ${ }^{2}$ Iron-molybdenum and iron-tungsten alloys have many points in common. Molybrlenum does not, however, appear to form a compound corresponding to $\mathrm{Fe}_{2} \mathrm{~W}$.

2 Quertler, in an article on molybdenum alloys (Z. Metallkunde 15, p. 252; 1923), stated that Lautsch and Tammann's (39) results were not considered as being fully satisfactory, so in another investigation, started but not completed, because of the death of the investigator, it was found that iron takes very generous amounts of molybdenum into solid solution, and that at still higher molybdenum contents a brittle iron-molybdenum compound appears. 


\section{MOLYBDENUM-IRON-CARBON}

This system has apparently not been inrestigated to any extent, although a good deal of work has been done on the properties of molybdenum steels. Guillet (26) in a systematic examination of the microstructure of molybdenum steels obtained results similar to those for tungsten steels. He found that, however, only about one-fourth the quantity of molybdenum is needed to produce equivalent results.

\section{NATURE OF CONSTITUENTS PRESENT IN ALLOY STEELS AND FERRO-ALLOYS}

The following survey of the data reported in the literature regarding the nature, composition, and structural formulas of many of the constituents found in alloy steels would indicate that our present knowledge on this subject is still far from being complete. Most of the data reported are based on chemical analyses of residues obtained from the solution of various steels and ferro-alloys. Mention is also made of carbides prepared in the electric furnace by $(a)$ reduction of oxides with carbon or a carbide, $(b)$ fusion of the alloying element in the presence of carbon, or $(c)$ treatment of the metal or oxide in carburizing gases. In this summary the different compounds are grouped under the alloy steel in which the compound might be present.

\section{CHROMIUM STEELS}

$\mathrm{Cr}_{3} \mathrm{C}_{2}$--Prepared in the electric furnace from chromium and a large excess of carbon, or by the reduction of chromium oxide witl calcium carbide (Moissan). Its existence in chromium steels was supported by Ruff and Foehr (55).

$\mathrm{Cr}_{5} \mathrm{C}_{2}$. - In residue from a high chromium-iron alloy containing up to 8.5 per cent $\mathrm{C}$; its presence in alloy checked by microscopic examination (Ruff and Foehr).

$\mathrm{Cr}_{4}$ C.-Product obtained in the above-mentioned chromium-carbon fusion (Moissan). Crystals of this compound assume hexagonal form. Ruff and Foehr did not find this compound in chromium steels. (See Arnold and Read, and also Murakami below.)

$3 \mathrm{Fe}_{3} \mathrm{C} . \mathrm{Cr}_{3} \mathrm{C}_{2}$. - In residue from two chromium steels (Carnot and Goutal).

$3 \mathrm{Fe}_{3} \mathrm{C}_{2} \mathrm{Cr}_{3} \mathrm{C}_{2}$.-Obtained by fusion in electric furnace of a mixture of chromic acid, iron, and coke (Williams), and also in residue from well-annealed chromium steels containing 15 to 24 per cent $\mathrm{Cr}$ and 0.65 to 0.85 per cent C (Arnold and Read). Murakami (44) questioned its existence and claimed that any excess iron or chromiur. 
carbide would, because of its insolubility in the acid solution used for dissolving the steel, be mixed with the double carbide; Edwards, Sutton, and Oishi (16) do not support him. Arnold and Read reported an isomorphous mixture of $\mathrm{Cr}_{3} \mathrm{C}_{2}$ or $\mathrm{Cr}_{4} \mathrm{C}$ with $\mathrm{Fe}_{3} \mathrm{C}$ in steels containing less than 10 per cent $\mathrm{Cr}$. They believed that $\mathrm{Cr}_{4} \mathrm{C}$ was found in well-annealed high chromium steels.

$\mathrm{Fe}_{3}$ C. $\mathrm{Cr}_{3} \mathrm{C}_{2}$. - In residue from ferrochromium (Carnot and Goutal). The belief that this double carbide exists in chromium steels was supported by Edwards, Sutton, and Oishi (16).

Murakami (44) reported that there were present in chromium steels three double carbides-alpha, $\left(\mathrm{Fe}_{3} \mathrm{C}\right)_{18} . \mathrm{Cr}_{4} \mathrm{C}$; beta, $\left(\mathrm{Fe}_{3} \mathrm{C}\right)_{9} . \mathrm{Cr}_{4} \mathrm{C}$; and gamma, $\mathrm{Fe}_{3} \mathrm{C} . \mathrm{Cr}_{4} \mathrm{C}$. He assumed the gamma carbide to dissociate into beta carbide and $\mathrm{Cr}_{4} \mathrm{C}$ at high temperature; beta carbide into alpha carbide and $\mathrm{Cr}_{4} \mathrm{C}$, and the $\mathrm{Cr}_{4} \mathrm{C}$ into $\mathrm{Cr}_{3} \mathrm{C}_{2}$ and $\mathrm{Cr}$. He claimed that he could identify these carbides by their behavior on etching.

\section{CHROMIUM-TUNGSTEN STEELS}

$3 \mathrm{Cr}_{3} \mathrm{C}_{2} \cdot \mathrm{W}_{2} \mathrm{C}$.- Obtained by treating in the electric furnace a mixture of chromic and tungstic acids with carbon or by fusing metallic chromium and tungsten with carbon (Moissan and Kowznetzow).

\section{TUNGSTEN STEELS}

$\mathrm{FeW}_{4}$.-Obtained in a ferrotungsten containing 93.4 per cent $\mathrm{W}$ (Norton).

$\mathrm{FeW}_{2}$.- - Residue from a ferrotungsten containing 86.4 per cent $\mathrm{W}$ (Polick and Grützner).

$\mathrm{Fe}_{3} \mathrm{~W}_{2}$. - Reported in ferrotungsten by De Benneville; obtained by Vigoroux from a mixture of $\mathrm{Fe}_{3} \mathrm{O}_{4}$ and $\mathrm{WO}_{2}$ by aluminothermic reaction.

$\mathrm{Fe}_{2} \mathrm{~W}$. - First isolated by Behrens. Its existence in tungsten steels and ferrotungstens supported by Carnot and Goutal, Swinden (though reported as $\mathrm{Fe}_{3} \mathrm{~W}$ ), Arnold and Read, Honda and Murakami, Hultgren $\left(\mathrm{Fe}_{\mathrm{n}} \mathrm{W}\right.$-this meaning either $\mathrm{Fe}_{3} \mathrm{~W}$ or $\mathrm{Fe}_{2} \mathrm{~W}$ ), and Ozawa.

$\mathrm{Fe}_{3} \mathrm{~W}$. - Carnot and Goutal reported it in ferrotungsten and also in the residue from 6 per cent tungsten and 0.4 to 0.5 per cent carbon steels. Gin reported its preparation by reducing ferrosilicon with tungstic acid in electric furnace.

$\mathrm{W}_{3}$ C.--Prepared by fusing metallic tungsten and carbon in electric arc furnace (Ruff and Wunsch, WC and compound assumed to be $\mathrm{W}_{2} \mathrm{C}$ also reported). Hultgren assumed a constituent present in the fused zone of tungsten, carburized by welding with a carbon electrode, to be $\mathrm{W}_{3} \mathrm{C}$. 
$\mathrm{W}_{2}$ C.-Obtained by the fusion of tungsten with an excess of carbon in electric furnace (Moissan). Andrews (2) reported, in determining the electrical conductance of tungsten filaments which had been carburized at incandescent temperatures, the breaks in the conductivity curve as due to the formation of $\mathrm{W}_{2} \mathrm{C}$ and $\mathrm{WC}$.

WC.-Found in a mixture of tungstic acid, iron, and coke heated in electric furnace (Williams). Obtained by treating tungsten powder or oxide in methane and hydrogen at $800^{\circ} \mathrm{C}$. (Hilpert and Ornstein, they also reported $\mathrm{W}_{3} \mathrm{C}_{4}$ formed by heating tungsten in $\mathrm{CO}$ at $1,000^{\circ}$ C.). Hultgren (35) and Arnold and Read (5) reported its presence in various tungsten steels and related alloys.

$2 \mathrm{Fe}_{3}$ C. $3 \mathrm{~W}_{2}$ C.- Found in a mixture of tungstic acid, iron, and coke heated in electric furnace (Williams).

$\mathrm{Fe}_{3}$ C.WC.-Residue from steels containing 6 to 8 per cent tungsten and 2 per cent carbon (Carnot and Goutal). Hultgren reported it as "Z1 carbicle," although Ozawa (50) in his microscopic examination of tungsten steels was not able to find it. Hultgren disagreed with Arnold and Rear (5) that a mixture of $\mathrm{Fe}_{3} \mathrm{C}$ and $\mathrm{WC}$ or of $\mathrm{WC}$ and $\mathrm{Fe}_{2} \mathrm{~W}$ rather than a double carbide is formed. Honda and Murakami (31) claimed the existence of a double carbide $\left(4 \mathrm{Fe}_{3} \mathrm{C} . \mathrm{WC}\right)$, and stated that it dissociates when heated to above $\mathrm{Ac}_{1}$, and that at a sufficiently high temperature WC reacts with iron to form $\mathrm{Fe}_{3} \mathrm{C}$ and $\mathrm{Fe}_{2} \mathrm{~W}$. Ozawa concluded that $\mathrm{Fe}_{3} \mathrm{C}$ and $\mathrm{Fe}_{2} \mathrm{~W}$ are mutually soluble to a certain concentration, and in stecls of high tungsten and carbon content these solid solutions decompose at about $900^{\circ} \mathrm{C} .\left(\mathrm{Fe}_{3} \mathrm{C}+\right.$ $\mathrm{Fe}_{2} \mathrm{~W}=\mathrm{WC}+5 \mathrm{Fe}$ ) ; this is not in agreement with Hultgren's conclusion that $\mathrm{WC}$ is dissolved in $\mathrm{Fe}_{3} \mathrm{C}$.

\section{VANADIUM STEELS}

VC.- Prepared by the reduction of $\mathrm{V}_{2} \mathrm{O}_{5}$ with carbon in the electric furnace (Moissan).

$\mathrm{V}_{2} \mathrm{C}_{3}$ (or $\mathrm{V}_{2 \mathrm{n}} \mathrm{C}_{3 \mathrm{n}}$ ).-Residue from steel containing 1.6 per cent vanadium and 2.0 per cent carbon (Putz).

$\mathrm{V}_{4} \mathrm{C}_{3}$.- - Residue from series of vanadium steels (Arnold and Read, who stated that no double carbide was formed, and that ranadium carbide formed a mechanical mixture with the iron carbide in steels below about 5 per cent vanadium and 1 per cent carbon). This form of carbide appears to be now generally accepted.

$\mathrm{Fe}_{3} \mathrm{C} .38\left(\mathrm{~V}_{3} \mathrm{C}_{2}\right)$.-Residue from steel containing 1.5 per cent vanadium and 0.4 per cent carbon (Nicolardet).

$\mathrm{Fe}_{3} \mathrm{C} .60\left(\mathrm{~V}_{4} \mathrm{C}_{3}\right)$. - Residue from steel containing 1.5 per cent vanadium and 0.8 per cent carbon (Nicolardet).

$\mathrm{Fe}_{3}$ C. $74\left(\mathrm{~V}_{4} \mathrm{C}_{3}\right)$. - Residue from ferrovanadium containing 32 per cent vanadium and 9 per cent carbon (Nicolardet). 


\section{MOLYBDENUM STEELS}

$\mathrm{Mo}_{2}$ C.--Obtained by heating molybdenum dioxide with excess carbon in the electric furnace (Moissan), also by heating molybdenum powder in methane at $1,000^{\circ} \mathrm{C}$. (Hilpert and Ornstein); in residue from molybdenum steels (Carnot and Goutal).

$\mathrm{Fe}_{2} \mathrm{Mo}, \mathrm{Fe}_{3} \mathrm{Mo}, \mathrm{FeMo}$, and $\mathrm{FeMo}_{2}$.-Found in ferromolybdenums (Vigoroux).

$\mathrm{Fe}_{3} \mathrm{Mo}_{2}$. - Residue from Mo. steels (Carnot and Goutal).

$\mathrm{Fe}_{3} \mathrm{Mo}_{3} \mathrm{C}$.- In residue from molybdenum steels. (Arnold and Read, Arnold and Ibbotson).

\section{HIGH-SPEED STEELS}

Various investigators have referred to the constituent present in these steels under different names, such as "carbide," "free carbide," "carbide particles," "double carbide," "double carbide of tungsten and iron," "iron-tungsten carbide," and "tungstide."

Bain and Jeffries (11) concluded from the results of their X-ray studies that the stable carbide in high-specd steels is iron-tungsten carbide, which is capable of retaining chromium and vanadium without altering the type of crystalline lattice; Westgren and Phragmén (65) suggested $\mathrm{Fe}_{8} \mathrm{~W}_{3} \mathrm{C}$ as the probable constitutional formula for this carbide. Grossman and Bain (23) state that about 30 per cent, by weight, of the high-speed steel consists of complex carbide, that in the annealed steel approximately all of the carbon, tungsten, and ranadium are found in the "carbide," together with about half of the chromium, and that under average hardening conditions somewhat less than one-half of this carbide is dissolved in the matrix when the steel is heated for quenching.

\section{MATERIALS AND METHODS}

Information concerning the various steels obtained for this investigation is given in Table 1. Some of these stecls were kindly furnished by the Ludlum Steel Co., Watervliet, N. Y., through R. P. Devries, formerly metallurgist, and by the Electric Alloy Steel Co., Charleroi, Pa., now a part of the Atlas Steel Corporation, Dunkirk, N. Y., through M. A. Grossman, formerly metallurgist; others were obtained from laboratory melts prepared at this bureau, some for this investigation and the rest for another unrelated investigation carried out at about the same time; and the balance consisted of stecls of a miscellaneous nature, largely high-speed steels, which were on hand at the bureau as stock material or specimens prepared in connection with other investigations. 
Three general etching methods were used: (a) Simple immersion, (b) electrolytic etching, and (c) heat tinting.

In riew of the uncertainties regarding the exact nature of the various constituents in alloy steels, the six types of constituents dealt with in this investigation will be designated by a general term, which indicates the character of the constituents without making any distinction as to whether it is a simple or complex compound and is a higher or lower form of carbide, ete. The six types of constituents studied are as follows: 

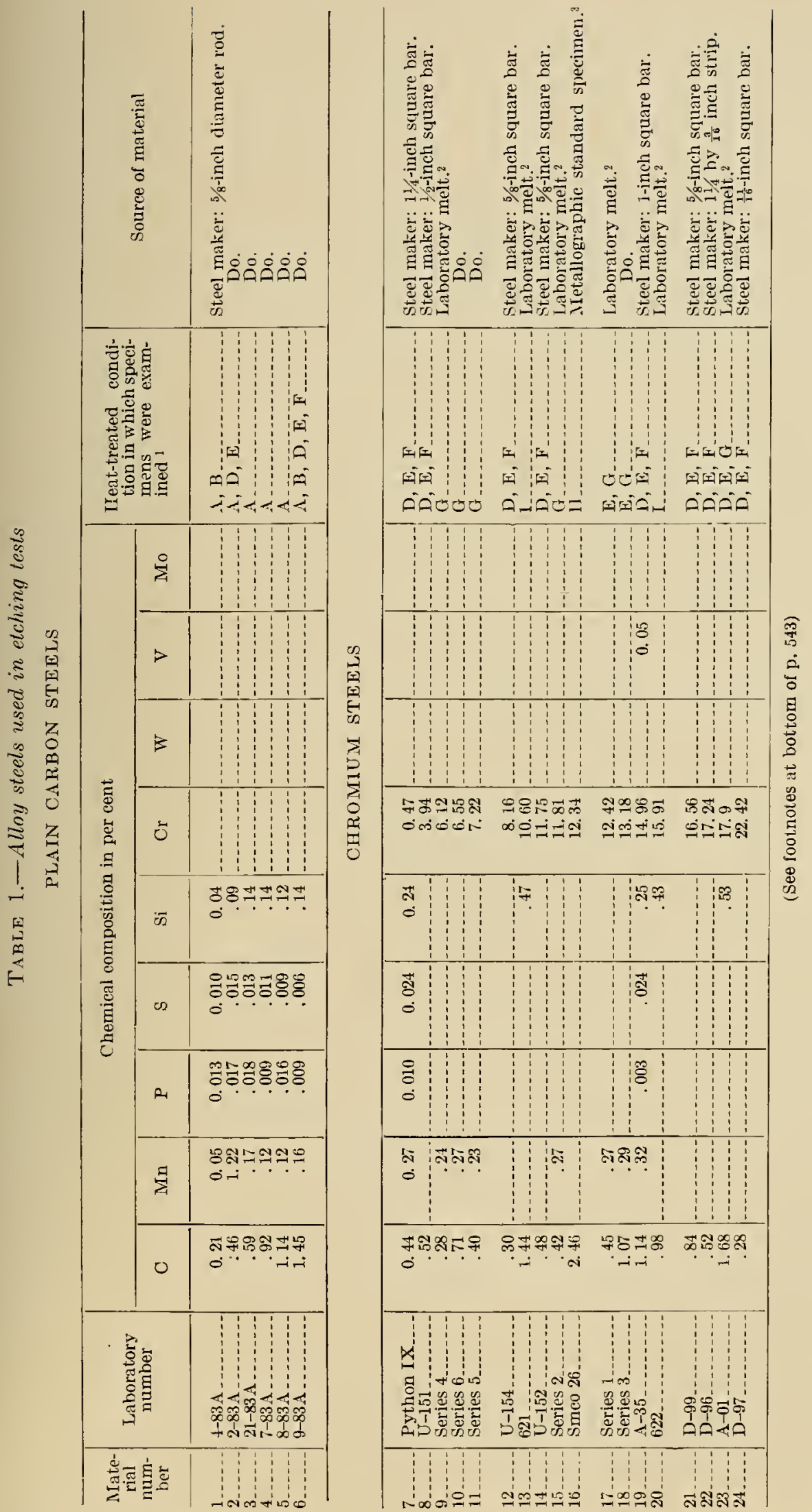

$56832^{\circ}-25 \dagger--2$ 

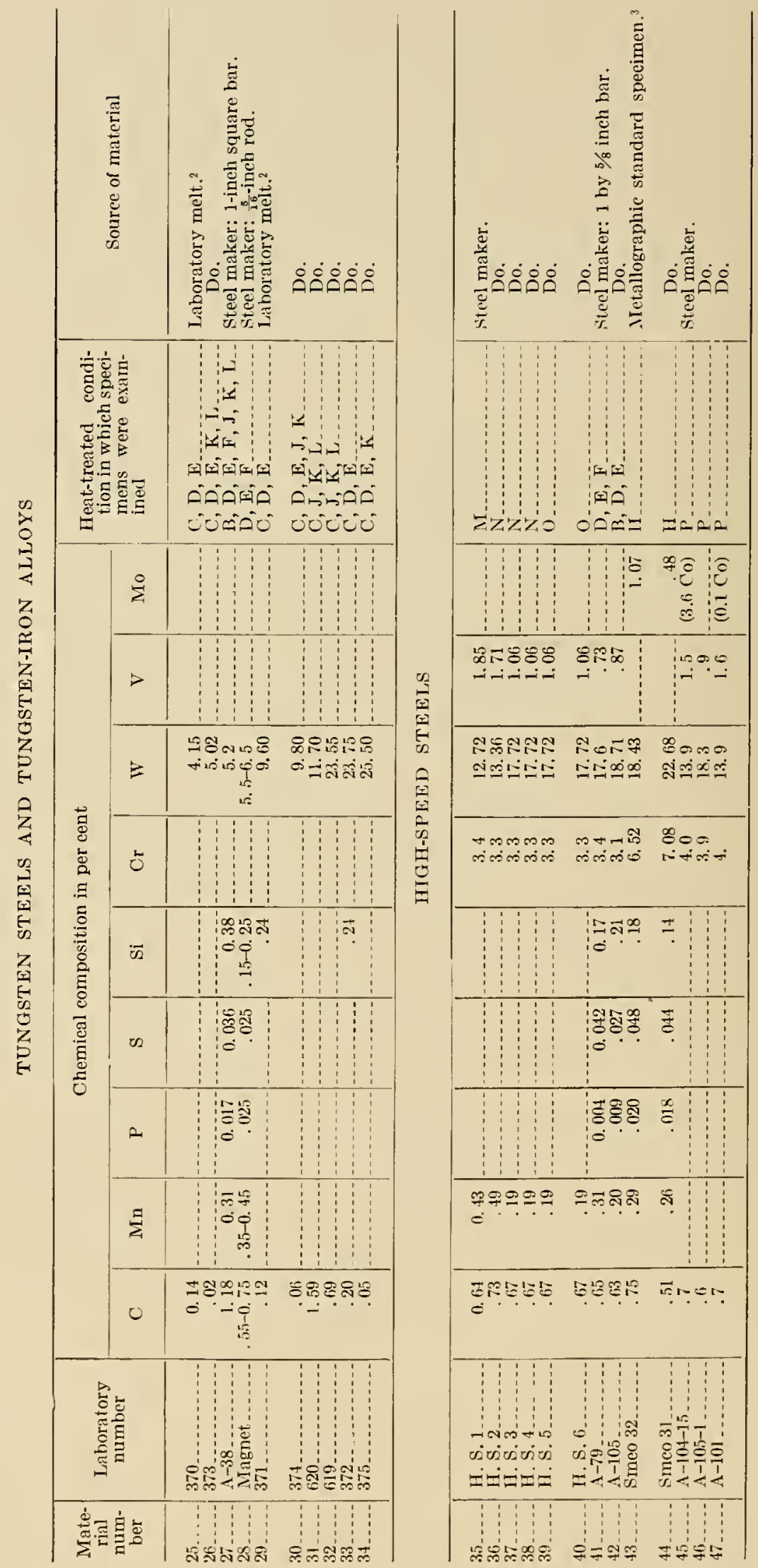

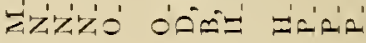

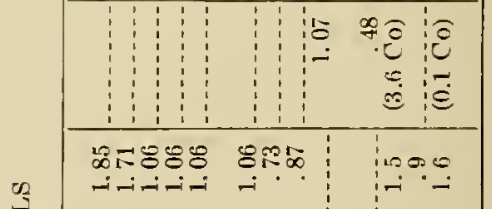

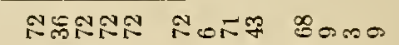
פேำ

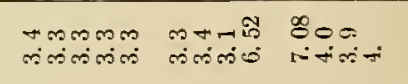

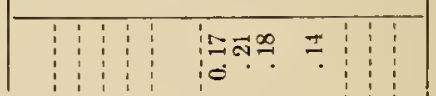

\begin{tabular}{l|l|l|l|} 
& & & \\
\hline & & & 0
\end{tabular}

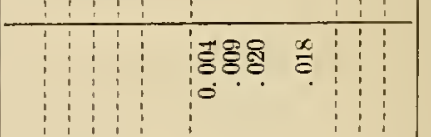

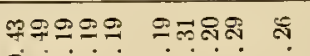

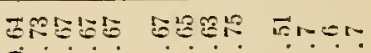

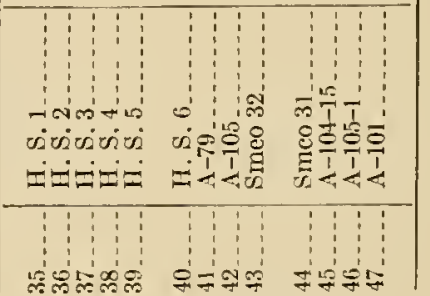




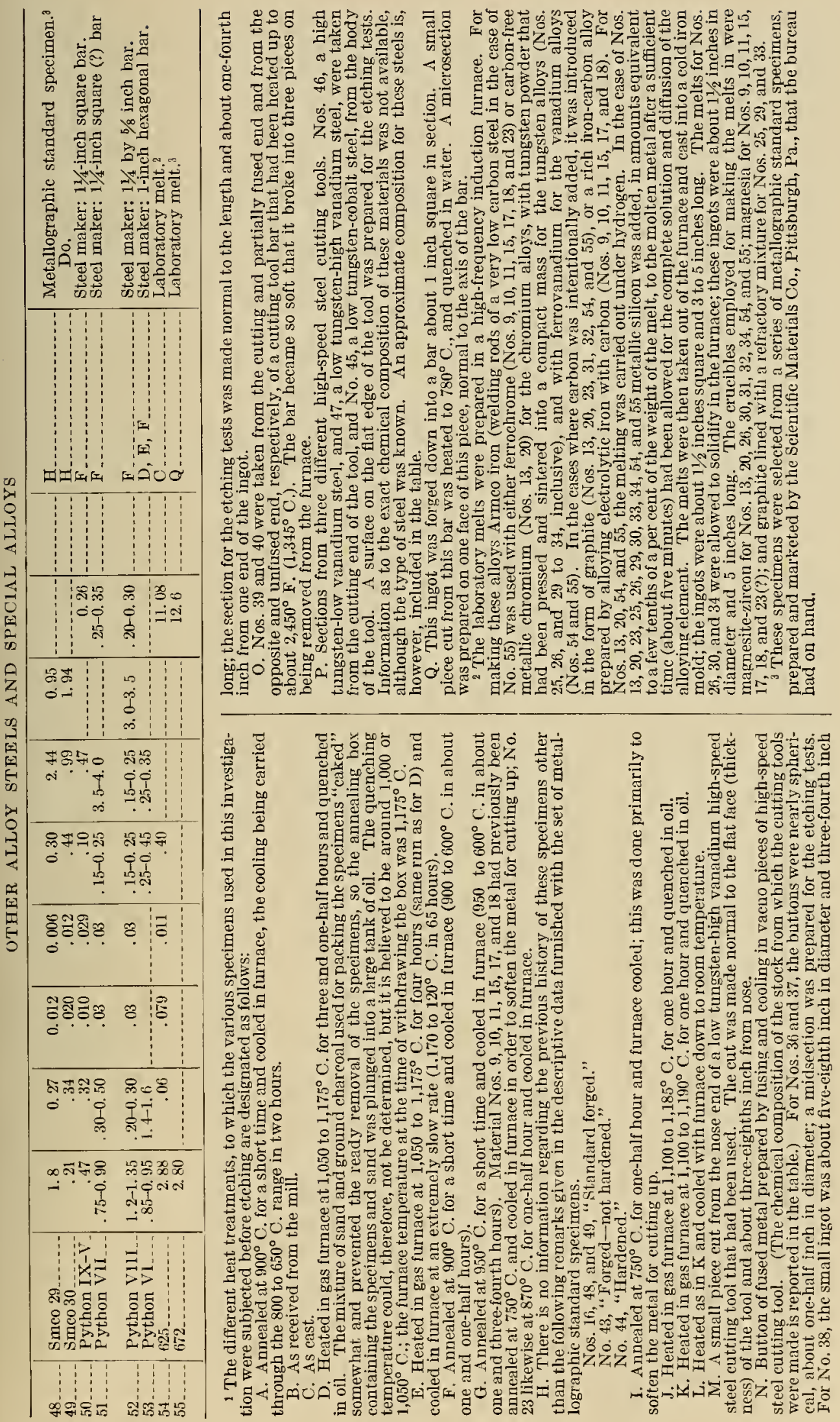


1. Iron Carbide, $\mathrm{Fe}_{3} \mathrm{C}$.- This is the only constituent whose chemical eomposition has been well established.

2. Chromum Carbide.-Irregular-shaped particles in iron-chromium-earbon alloys.

3. Tungsten Carbide.-Only the very hard, angular-shaped particles, assumed to be $\mathrm{WC}$, were eonsidered.

4. Vanadium Carbide.-This eonstituent, $\mathrm{V}_{4} \mathrm{C}_{3}$ (Arnold and Read), occurs as more or less rounded, hard particles in high-carbon, high-vanadium steels, and in conjunction with cementite in steels of lower carbon and vanadium eontent.

5. Iron Tungstude.-Partieles of no definite shape found in irontungsten and iron-tungsten-carbon alloys. Its formula is now quite generally considered as $\mathrm{Fe}_{2} \mathrm{~W}$.

6. H. S. S. Constituent (high-speed steel eonstituent).-More or less globular-shaped partieles found throughout the matrix of such steels in the forged condition.

\section{EXPERIMENTAL RESULTS}

\section{ETCHING BY IMMERSION}

(a) PRELIMINARY TESTS

In order to get a line on the method of proeedure to follow at the outset of this investigation, some etching tests were undertaken on one specimen each of four types of steel, as follows: (a) Chromium steel, 15.0 per cent chromium and 1.1 per eent carbon (19, F; Table 1 ); (b) tungsten steel, 5.2 per cent tungsten and 1.2 per cent carbon $(27, \mathrm{~F}) ;(c)$ high-speed steel $(41, \mathrm{~F})$; and $(d)$ a plain high-earbon steel, 1.5 per cent carbon $(6, \mathrm{~F})$.

Several etching reagents of an acidic nature and three other eommonly used ones, giving an alkaline reaction, were tried out on these steels, as follows:

Acidic Reaction.-

(a) Two per cent alcoholic solution of nitrie acid.

(b) Chromic oxide-sulphuric acid mixture (3 g of chromic oxide, 35 cc concentrated sulphuric acid and 65 ce water, recommended by Robin (54) for ferroalloys, such as ferrochromium and ferronickel.

(c) Three per cent aqueous solution of sulphurous acid, recommended by Hilpert and Colver-Glauert (30) for distinguishing cementite in hardened and tempered stecls.

(d) Alcoholic-aqueous solution of picric acid (4 parts of a saturated alcoholic solution of pieric acid and 1 part of water).

(e) Five per cent aqueous solution of ammonium persulphate-Rawdon (53). The action of this solution is, througl hydrolysis, that of a weak acid intensified by the presence of oxygen.

Alkaline Reaction.-

( $S$ ) Alkaline solution of sodium picrate (Kourbatoff's reagent; $2 \mathrm{~g}$ picric acid dissolved in $98 \mathrm{ec}$ of 25 per cent aqueous solution of sodium hydroxide. 
(g) Sodium hydroxide solution and hydrogen peroxide mixture, Yatsevitch's reagent (68); 2 parts by volume of 10 per cent aqueous sodium hydroxide solution and 1 of hydrogen peroxide solution.

(h) Alkaline potassium ferricyanide solution recommended by Murakami (44) for darkening carbides in chromium steels; $10 \mathrm{~g}$ potassium ferricyanide and $10 \mathrm{~g}$ potassium hydroxide to $100 \mathrm{ec}$ water.

It was seen at once from the results of these tests that the acid etching reagents offered no promise of distinguishing the various carbides from one another, for in all cases the carbide particles remained apparently uncolored and stood out in strong relief in a matrix, which was more or less uniformly and deeply corroded. The disadvantage of the possible removal from the microsection, mechanically through the general corroding away of the matrix, of small or rery small particles of carbide or of a special constituent embedded in the matrix was also recognized. The results obtained with the alkaline reagents offered a more promising line of study. Althougl no satisfactory distinction could be made between the carbides of iron, chromium, and tungsten when etched with reagent $(g)$ or $(h)$, iron carbide differed from the chromium and tungsten carbides in the behavior to reagent $(f)$. The effect produced by reagent $(h)$ upon the chromium and tungsten carbides was also different from that by reagents $(f)$ and $(g)$.

This difference in behavior prompted further study of the underlying cause of the effects of these three alkaline etching reagents. It had previously been assumed that the effects produced were due, at least in part, to the presence of nascent oxygen formed in the reaction between the solution and the metal specimen or by a decomposition of the compound in the solution. Yatseritch (68) had concluded that the presence of oxygen was needed in conjunction with the sodium hydroxide solution to produce the desired etching effect, that is, by darkening, upon the particles of "carbides of tungsten" present in high-speed steels or tungsten steels. It will be shown later in this paper that these constituents are darkened by sodium hydroxide alone.

\section{(b) TESTS IN NEUTRAL AND ALKALINE SOLUTIONS WITH AND WITHOUT OXYGEN}

For these tests the six chosen types of constituents were employed. Various steels containing these constituents were used; these specimens were in differently heat-treated conditions (Table 1 ). Table 2 gives the results of these tests, the effect produced upon the various constituents by the etching reagent in question being indicated by black-faced type if darkened, and by roman type if the constituent was not darkened. 
TABLE 2.-Constituents in alloy steels darkened or not darkened by immersion in various etching reagents

In the cases where the constituent was darkened (indicated by black-faced type) the minimum time (in minutes) required to give a complete darkening is indicated in those cases wbere no darkening (in roman type) was produced the constituent remained undarkened after the specimens containing this constituent had been immersed for the time stated]

\begin{tabular}{|c|c|c|c|c|c|c|c|c|c|c|c|}
\hline \multirow{5}{*}{$\begin{array}{l}\text { Constituent } \\
\text { (see p. 544) }\end{array}$} & \multicolumn{11}{|c|}{ Etching reagent } \\
\hline & \multicolumn{4}{|c|}{$\mathrm{NaOH}$ solution $\mathrm{I}$} & \multicolumn{4}{|c|}{$\mathrm{NaOH}$ solution and oxidizer } & \multirow{4}{*}{$\begin{array}{l}\mathrm{NH}_{4} \mathrm{OH} \\
\text { dilute } \\
\text { solution, } \\
3 \text { per } \\
\text { cent } \\
\mathrm{NH}_{3}, \text { by } \\
\text { weight, } \\
\text { boiling } \\
\text { point }\end{array}$} & \multicolumn{2}{|c|}{ Na picrate } \\
\hline & \multirow[t]{2}{*}{$\mid \begin{array}{c}\text { Room } \\
\text { tem- } \\
\text { pera- } \\
\text { ture }\end{array}$} & \multicolumn{3}{|c|}{ Boiling point } & \multicolumn{2}{|c|}{$\begin{array}{l}10 \text { per cent } \\
\text { alkali }\end{array}$} & \multicolumn{2}{|c|}{$\begin{array}{l}20 \text { per cent } \\
\text { alkali }\end{array}$} & & \multirow{2}{*}{$\begin{array}{l}\text { Neu- } \\
\text { tral } \\
\text { solu- } \\
\text { tion }\end{array}$} & \multirow{2}{*}{$\begin{array}{l}\text { Alka- } \\
\text { line } \\
\text { solu- } \\
\text { tion }\end{array}$} \\
\hline & & \multicolumn{3}{|c|}{ Per cent alkali } & $\mathrm{O}_{2}$ gas & $\mathrm{H}_{2} \mathrm{O}_{2}{ }^{2}$ & $\mathrm{O}_{2}$ gas & $\mathrm{H}_{2} \mathrm{O}_{2}$ & & & \\
\hline & 10 & 10 & 25 & 50 & \multicolumn{2}{|c|}{$\begin{array}{c}\text { Room tem- } \\
\text { perature }\end{array}$} & \multicolumn{2}{|c|}{ Boiling point } & & \multicolumn{2}{|c|}{ Boiling point } \\
\hline $\begin{array}{l}\text { Iron carbide }\left(\mathrm{Fe}_{3} \mathrm{C}\right)_{--} \\
\text {Chromium carbide... } \\
\text { Tungsten carbide-..- } \\
\text { Vanadium earbide } \\
\text { Iron tungstide }\left(\mathrm{Fe}_{2} \text { WW }\right. \\
\text { H. S. S. constituent - }\end{array}$ & $\begin{array}{r}\text { IFin. } \\
30 \\
40 \\
30 \\
30 \\
\mathbf{1 - 5} \\
\mathbf{1 0}\end{array}$ & $\begin{array}{r}\text { Min. } \\
5-10 \\
20 \\
7 \\
17 \\
1 \\
10\end{array}$ & $\begin{array}{r}\text { Min. } \\
5 \\
510 \\
65 \\
65 \\
61 / 2 \\
10\end{array}$ & $\begin{array}{r}\text { Min. } \\
63 \\
65 \\
63 / 4 \\
65 \\
65 \\
1 / 2 \\
63 / 4\end{array}$ & $\begin{array}{r}\text { Min. } \\
30 \\
30\end{array}$ & $\begin{array}{r}\text { Min. } \\
18 \\
45 \\
16 \\
40 \\
\mathbf{1} \\
\mathbf{3 - 5}\end{array}$ & $\begin{array}{r}\text { Min. } \\
\mathbf{2 0} \\
\mathbf{1 5} \\
25 \\
25 \\
\mathbf{1 0}\end{array}$ & $\begin{array}{r}\operatorname{Min} \\
\pm 5 \\
4\end{array}$ & $\begin{array}{r}\text { Min. } \\
10 \\
10 \\
10 \\
10 \\
10 \\
10\end{array}$ & $\begin{array}{r}\text { rin. } \\
60 \\
25 \\
30 \\
30 \\
1 \\
10\end{array}$ & $\begin{array}{r}1 \text { Iin. } \\
\mathbf{5}-\mathbf{1 0} \\
30 \\
20 \\
15 \\
9 \\
11 / 2\end{array}$ \\
\hline
\end{tabular}

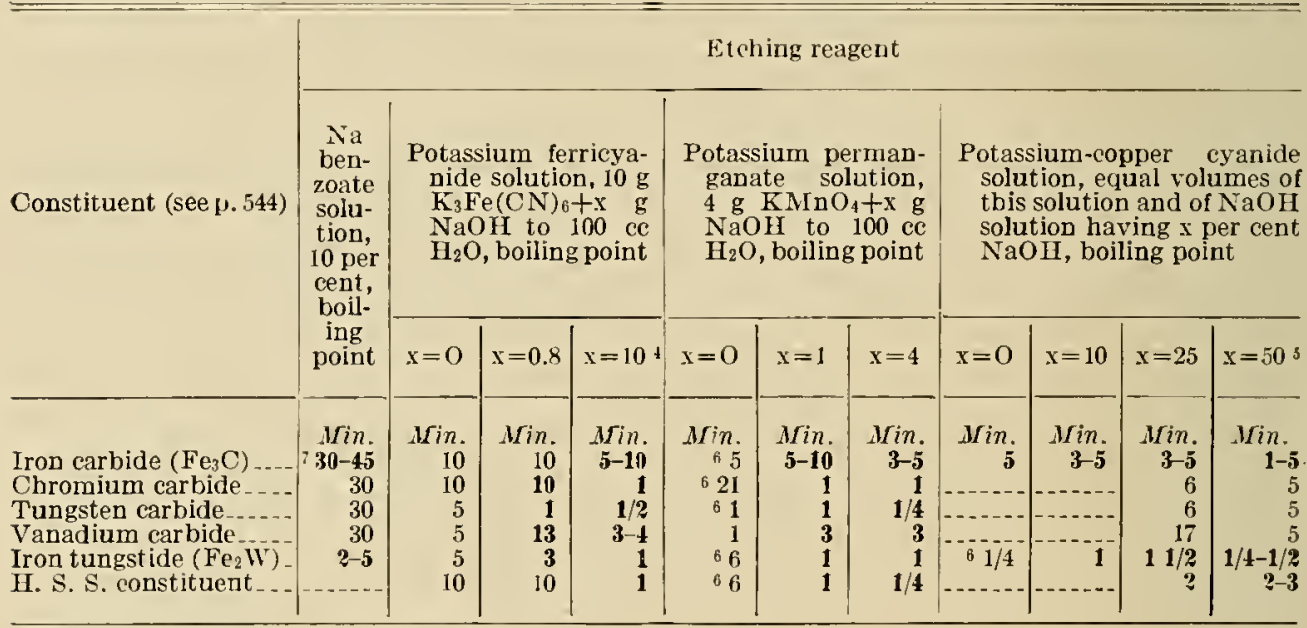

1 KOll solution gave similar results

2 Yatsevitch's reagent.

${ }^{3}$ Kourbatoff's reagent.

- Murakami's reagent.

5 Tbompson and Whitehead's reagent

6 Matrix of microsection more or less strongly tatn shed.

7 The carbide lamellas were strongly darkened, while the globular particles were still ratber lightly colored.

In a majority of cases the particles of the constituent were "eaten out," as indicated by the hollow appearance of the spaces originally occupied by the particles. A slight repolishing of the etched section confirmed the existence of these dark-walled carities. In other cases the particles appeared to be merely darkened over their surface. These two types of attack did not appear to be related to the nature of the constituent etched but rather to the circumstances of etching. The terms "darkened" and "dlarkening" used throughout this paper applies to both these types, no distinction being made between 
the two. Where the etching had not been carried on for a sufficiently long time, a part of the particle remained unattacked and was surrounded by a dark area, representing the eaten out portion; the eating away of the particles generally proceeded inwards from the edge. Figure $4, d$, on page 548 gives an illustration of this.

1. Sodium or Potassium Hydroxide Solution.-A study was first made of the specific influence exerted by the alkali in the etching effects produced under nonoxidizing and oxidizing conditions. When etched at room temperature under nonoxidizing conditions, only the iron tungstide and high-speed steel constituent were darkened, the former more quickly than the latter, by a 10 per cent, by weight, solution of sodium hydroxide or potassium hydroxide, while the matrix remained bright. Iron carbide remained undarkened after 30 minutes' immersion at room temperature, but was readily darkened in 5 to 10 minutes by the boiling solution. Iron tungstide was darkened by the boiling solution in 1 minute, while the high-speed steel constituent required about the same time (10 minutes) as at room temperature. Etching with a hot 25 per cent solution yielded no materially diffcrent results, although the matrix of the specimens containing chromium carbide, tungsten carbide, or vanadium carbicle became more or less tarnished by the formation of a thin reddishbrown film, presumably iron oxide, over portions of the matrix. The higher concentration of alkali in a 50 per cent solution hastened somewhat the darkening of iron carbide, iron tungstide, and the high-speed steel constituent and produced still greater tarnishing; in addition, the matrix of the iron carbide and high-speed steel specimens were also tarnished. This tendency to tarnishing, which is less in cases where the constituent, such as iron tungstide, is easily attacked by the alkali, would obviously reduce the value of concentrated alkaline etching solutions. This might, however, be avoided by the incorporating in the alkaline solution of some compound that would retard the tarnishing. Several etching solutions, proposed by various investigators, and which will be discussed later on, appear to fall within this category.

Oxygen was next passed from a tank of the gas into the alkaline solution, in which the specimen was placed with the polished face up, so that the stream of gas impinged directly upon the middle of the polished face. An exposure of 30 minutes to the gas in a 10 per cent aqueous potassium hydroxide solution at room temperature failed to darken iron carbide or chromium carbide, while an 11-minute exposure darkened the particles of high-speed steel constituent (41, F, Table 1) lying outside of the zone covered by the stream of gas more fully than those lying within this zone. One hour's etching in a 20 per cent potassium hydroxide solution under similar conditions did not darken chromium carbide. In a hot 20 per cent sodium 


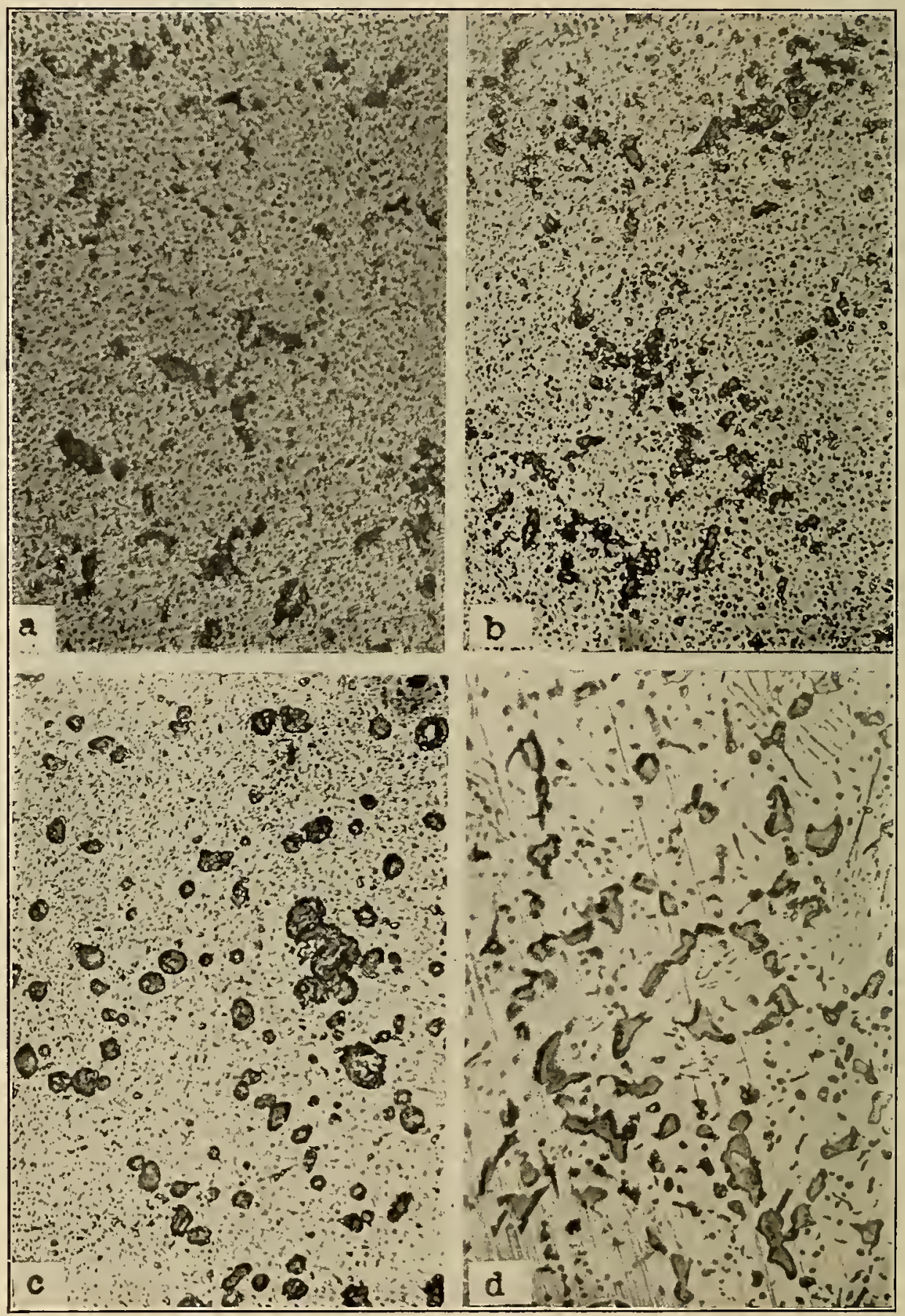

FIG. 4.-Microstructures illustrating the ctcling (ffects produced upon the particles of the structurally free constituent present in specimens of chromium, high-spced, and plain carbon stecls. $\times 500$

(a) and $(b)$ : chromium steel containing 15.0 per cent $\mathrm{Cr}$. and 1.1 per cent $\mathrm{C}$. (19, F; Tahle I). (c): high tungsten-low vanadium high-speed stecl $(41, \mathrm{~F})$.

(d): 1.45 per cent carbon steel (i, F).

(a) Etched with hot alkaline potassium ferricyanide solution (M furakami's reagent) for 1 minute, (b) and $(c)$, with hot alkaline potassium permanganate solution for 1 minute, and $(d)$, with hot alkaline sodiun picrate solution (Kourbatoff's reagent) for 10 minutes.

Note that in $d$, the eating out of the $\mathrm{Fe}_{3} \mathrm{C}$ particles had started along the borders of the particles. 
hydroxide solution chromium carbide and tungsten carbide remained undarkened after 15 and 25 minutes' immersion, respectively; irou carbide and high-speed steel constituent were, in 20 and 10 minutes, respectively, darkened uniformly orer the microsection and apparently independent of any possible influence exerted by the oxygen.

The addition of hydrogen peroxide to the alkaline solution was next tried to determine whether or not nascent oxygen would produce different results. A 6 minutes' immersion in a 10 per cent potassium hydroxide solution, with $10 \mathrm{cc}$ doses of 3 per cent hydrogen peroxide solution added from time to time, failed to darken cliromium carbide, whereas the high-speed steel constituent was quite strongly darkened in 3 minutes. Etching in a hot 20 per cent sodium hydroxide solution, with hydrogen peroxide added in like manner, yielded similar results; chromium carbicle remained undarkened after 4 minutes while the high-speed steel constituent was fully darkened in 1 minute and the iron carbide in 6 minutes.

It was found by electrolytic etching (Sec. VI, 2) that ammonia solution attacked the carbides of chromium, tungsten, and vanadium readily, the iron carbide and iron tungstide at a much slower rate. However, none of the constituents were darkened by a 10 minutes' immersion in hot solutions of ammonia.

2. Sodrum Picrate Solutron.-The alkaline solution of sodium picrate, generally used for identifying iron carbide in carbon steels, darkens iron tungstide and the high-speed steel constituent more quickly than iron carbide. This is in agreement with Honda and Murakami's (31) statement that iron tungstide is more casily colored than cementite. Chromium carbide, tungsten carbide, and ranadium carbide remained bright when exposed as indicated in Table 2; Guillet (26) and Murakami (44) reported that chromium carbide is not darkened by this reagent. In this investigation an etching period of no less than 5 to 10 minutes was necessary to darken fully the iron carbide in carbon steels.

Loskiewicz (41) has given results obtained with three alkaline solutions at $100^{\circ} \mathrm{C}$. on a 0.3 per cent carbon steel, carburized to an approximate carbon content of 1.5 per cent. With an alkaliue sodium picrate solution (5 g picric acid and $20 \mathrm{~g} \mathrm{NaOH}$ to $100 \mathrm{cc}$ $\mathrm{H}_{2} \mathrm{O}$ ) and alkaline plumbite solution $(5 \mathrm{~g} \mathrm{PbO}$ and $20 \mathrm{~g} \mathrm{NaOH}$ to 100 cc $\mathrm{H}_{2} \mathrm{O}$ ), 20 or more minutes were needed, and with an alkaline potassium ferricyanide solution $\left(20 \mathrm{~g} \mathrm{~K}_{3} \mathrm{Fe}(\mathrm{CN})_{6}\right.$ and $10 \mathrm{NaOH}$ to $100 \mathrm{cc} \mathrm{H}_{2} \mathrm{O}$ ) about 15 minutes sufficed. The etching time increased with increasing dilution of solution.

To determine whether or not the action of alkaline sodium picrate solution is largely, if not entirely, due to excess hydroxide in the sodium picrate solution, tests were made with neutral sodium picrate prepared in the following manner: A saturated aqueous solution 
of picric acid was added to a strong aqueous sodium hydroxide solution, whereupon a bright yellow precipitate, sodium picrate, formed in abundant quantity. The filtered precipitate was allowed to drain as free from alkaline liquid as practicable and to dry in the air. A dilute aqueous picric acid solution was then added to an aqueous solution of this sodium picrate until the latter reacted neutral to litmus paper. Etching tests made with a boiling solution showed that iron tungstide ${ }^{3}$ was readily darkened by a neutral 1 per cent, by weight, sodium picrate solution, while the high-speed steel constituent was undarkened after 10 minutes' immersion. Iron carbicle remained undarkened after 60 minutes' immersion in a hot 10 per cent solution. A probable explanation for the effect produced on the iron tungstide is that sodium hydroxide was formed by hydrolysis in the neutral sodium picrate solution in sufficient quantity to affect the iron tungsticle but not the other two constituents. It is of interest to note in passing that Matweieff has been reported to have used neutral sodium picrate for distinguishing between iron phosphide and iron carbide, the former being attacked by this reagent.

These tests appear to show that the etching by alkaline sodium picrate reagent of iron carbide and high-speed steel constituent is due mainly, if not entirely, to the alkali present; and likewise for iron tungstide. Neutral sodium picrate is the only reagent in this investigation that offers an apparently positive means of distinguishing iron tungstide from the high-speed steel constituent.

Since alkaline sodium benzoate $(6.3 \mathrm{~g}$ benzoic anhydride and 20 g sodium hydroxide to 100 cc water), which Thompson and Whitehead (61) found to darken iron carbide, appeared to come in the class with alkaline sodium picrate, tests were made with this solution. The constituents responded in very much the same way as to the picrate solution, although iron carbide was much more slowly darkened, which may be explained by the smaller proportion of free alkali in the benzoate solution.

3. Potassium Ferricyanide Solution.-Murakami (44) appears to be the first to have used an alkaline solution of potassium ferricyanide as an etching reagent. He found that chromium carbide is darkened by this solution. Honda and Murakami (32) found this solution satisfactory for darkening the high-speed steel constituent and reported 10 to 15 seconds' etching at room temperature to be sufficient. No tests were made in this investigation to check this statement, 1 minute in either the cold or hot solution was found to be amply sufficient.

\footnotetext{
${ }^{3}$ In etching the iron tungstide specimens the color cf the solutions changed from a strong yellow to yellowhrown or red-brown, and a quite firmly adhering brown colored film was formed over the microsection. This film was easily removed during the washing of the specimens hy rubbing the etched surfaee with a wad of cotton soaked in a very dilute aqueous hydrochloric acid solution.
} 
When used hot, this alkaline potassium forricyanide solution was found to darken all the constituents covered in this investigation (Table 2), although the action on the iron carbide was appreciably slower, a fact already noted by Daeves (15) (see reference to Loskiewicz, p. 549). The chromium carbide is quite strongly darkened at room temperature, though more slowly than by the hot solution.

The etching effects produced by this alkaline solution are evidently due to nascent oxygen generated in the reaction occurring between the potassium ferricyanide and alkali in the presence of and in close conjunction with the specimen, probably in intimate contact with the polished microsection. The iron matrix appears to be rendered passive by the oxygen and possibly by any excess alkali present in the solution; the constituents are thus more readily oxidized and eaten out, as evidenced by the presence of dark-walled cavities in the etched section, while the matrix remains apparently unaffected. Mercer ${ }^{4}$ advanced the hypothesis, many years ago, that when potassium hydroxide is brought into contact with potassium ferricyanide the deficiency in the potassium atoms of the latter is supplied, but that this affinity is not strong enough to liberato oxygen. When a second body having an attraction for oxygen is present in conjunction with the potassium hydroxide and potassium ferricyanide in solution, this second affinity, acting in a different direction, withdraws the oxygen and allows the potassium atom to combine with the potassium ferricyanide to form potassium ferrocyanide.

The constituents in the steel, iron carbide, etc., should correspond to the "second body having an attraction for oxygen" and be attacked by the alkaline ferricyanide solution in preference to the surrounding iron matrix because of the former's greater susceptibility to oxidation and the latter's assuming the passive condition. Daeves (15) states that alkaline potassium ferricyanide solution is slowly decomposed, cold, and quite rapidly on heating, with the formation of ferrocyanide compounds; he offered no suggestion as to the important rôle played by the oxygen.

To test out the influence of oxygen, etching tests were made in a boiling aqueous potassium ferricyanide solution, 10 per cent, but with no addition of alkali. This neutral solution, in which no oxygen should be developed, failed to darken any of the constituents, even after 5 to 10 minutes' immersion. Next, a solution of the same concentration with a small amount of alkali, less than one-tenth of that in Murakami's reagent, bcing added, was tried. Tungsten carbide was readily darkened, while chromium and vanadium carbides and iron tungstide were weakly attacked; iron carbide and high-

${ }^{4}$ Mercer, Philosophical Mag. (3), 31, p. 126; 1847. 
speed steel constituent remained unaffected after 10 minutes' exposure. Chromium carbide was strongly darkened, and the highspeed steel constituent quite strongly so, when the amount of alkali was increased to about three-tenths of that in Murakami's reagent: iron carbide remained still undarkened after 10 minutes' immersion.

Hydrogen peroxide was next added to a hot 10 per cent aqueous solution of potassium ferricyanide to determine whether or not the oxygen liberated, according to the following reaction-

$$
4 \mathrm{~K}_{3} \mathrm{Fe}(\mathrm{CN})_{6}+2 \mathrm{H}_{2} \mathrm{O}_{2}=3 \mathrm{~K}_{4} \mathrm{Fe}(\mathrm{CN})_{6}+\mathrm{H}_{4} \mathrm{Fe}(\mathrm{CN})_{6}+2 \mathrm{O}_{2}
$$

would yield similar results as the alkali with the potassium ferricyanide solution. Five minutes' etching in this failed to darken any of the constituents. Small portions of hydrogen peroxide solution were added to the ferricyanide solution frequently during the etching period; the ferrite matrix of the tungsten carbide, iron tungstide, and vanadium carbide specimens was found to be badly pitted or corroded in places. A possible explanation for this is that the iron matrix, not having been rendered passive, through the lack of an intimate contact with nascent oxygen, was attacked by the hydroferrocyanic acid formed in the reaction. Although there was an evolution of oxygen gas during the etching in this mixture, the reason that none of the constituents were darkened appears to be due to the lack of intimate contact between the rising bubbles of oxygen and the polished surface.

Next, etching in a hot alkaline solution, to which hydrogen peroxide was added successively in small doses, was tried on several plain carbon steels in order to determine whether or not the augmentation in the supply of oxygen would hasten the etching effect on iron carbide which is but slowly darkened by the alkaline solution without oxidizer. According to Baumann ${ }^{5}$ the reaction produced is as follows:

$$
2 \mathrm{~K}_{3} \mathrm{Fe}(\mathrm{CN})_{6}+2 \mathrm{KOH}+\mathrm{H}_{2} \mathrm{O}_{2}=2 \mathrm{~K}_{4} \mathrm{Fe}(\mathrm{CN})_{6}+2 \mathrm{H}_{2} \mathrm{O}+\mathrm{O}_{2}
$$

The results were substantially the same : s those obtained in the alkaline solution without hydrogen peroxide added.

Daeves (15) has proposed a modification of Murakami's reagent, the amount of potassium ferricyanide being doubled, while that of sodium hydroxide is kept the same as the weight of potassiun hydroxide in Murakami's formula. A consideration of the proportions used by both Murakami and Daeres, with respect to the amounts of ferricyanide and alkali required to satisfy the equation (theoretically, 5.9 and 8.2 parts $\mathrm{K}_{3} \mathrm{Fe}(\mathrm{CN})_{6}$ to 1 part $\mathrm{KOH}$ and $\mathrm{NaOH}$, respectively), will show that thre should be less excess of

5 Baumann, Zeit. angewandte Chemie, p. 113; 1892. 
alkali left after all the ferricyanide had been reacted upon by the alkali present in Daeves's reagent than in Murakami's. Etching tests with this modified alkaline ferricyanide solution were made only on iron carbide, chromium carbide, and iron tungstide specimens with results very similar to those obtained with Murakami's reagent.

4. Potassium Permanganate Solution.-Potassium permanganate in acid solution is used extensively as an oxidizing agent, and the use of this compound in an alkaline solution suggested itself after the "mechanism" of the etching effect of Murakami's reagent became understood. With this compound in the presence of sufficient potassium or sodium hydroxide nascent oxygen should be cxpected to form according to the following equations ${ }^{6}$

or

$$
4 \mathrm{KMnO}_{4}+4 \mathrm{KOH}=4 \mathrm{~K}_{2} \mathrm{MnO}_{4}+2 \mathrm{H}_{2} \mathrm{O}+2 \mathrm{O}
$$

$$
4 \mathrm{KMnO}_{4}+4 \mathrm{NaOH}=2 \mathrm{~K}_{2} \mathrm{MnO}_{4}+2 \mathrm{Na}_{2} \mathrm{MnO}_{4}+2 \mathrm{H}_{2} \mathrm{O}+2 \mathrm{O}
$$

Tests were made with two solutions used hot. One contained $40 \mathrm{~g}$ of potassium permanganate and $10 \mathrm{~g}$ sodium hydroxide $(14 \mathrm{~g}$ potassium hydroxide) to the liter, and the other the same amount of permanganate and four times the amount of hydroxide. All the constituents were darkened to a similar extent as by Murakami's reagent (Table 2). The more strongly alkaline solution was somewhat more rapid in action than Murakami's reagent, particularly with iron carbide and high-speed steel constituent. Those constituents, which were readily darkened in the hot solutions, were darkened when etched at room temperature, although at a slower rate. No improvement was gained by the addition of hydrogen peroxide to the alkaline permanganate solution. Figure $4, a$ and $b$, shows chromium carbide etched with Murakami's reagent and the alkaline potassium permanganate. Figure $4, c$, shows clearly the very small particles embedded in the matrix of a high-speed steel specimen (41, F, Table 1 ).

Etching in a hot neutral aqueous potassium permanganate solution (40 $\mathrm{g} \mathrm{KMnO}_{4}$ per liter) failed to darken any of the constituents (Table 2). The matrix of all the specimens were more or less strongly tarnished.

To show further that nascent oxygen is responsible for the effect produced by the alkaline permanganate solution, a chromium carbide specimen was immersed for five minutes in a hot solution $(4 \mathrm{~g}$ $\mathrm{KMnO}_{4}$ and $1 \mathrm{~g} \mathrm{NaOH}$ to $100 \mathrm{cc}_{2} \mathrm{O}$ ), to which pyrogallic acid ( $1 \mathrm{~g}$ to $25 \mathrm{cc}_{2} \mathrm{O}$ ) had been added immediately before the immersion of the specimen. The chromium carbide was not at all darkened, and the matrix remained bright and clean. The pyrogallic acid in alkaline solution is a strong reducing agent, and cridently all the available oxygen was used in oxidizing this compound.

o Rammelsberg, Ber., 8, p. 232; 1875. 
Potassium dichromate in acid solution is a powerful oxidizing compound. It will be seen, however, from the following typical equation, that no oxygen is formed in the reaction between

$$
\mathrm{K}_{2} \mathrm{Cr}_{2} \mathrm{O}_{7}+2 \mathrm{KOH}=2 \mathrm{~K}_{2} \mathrm{CrO}_{4}+\mathrm{H}_{2} \mathrm{O}
$$

dichromate and alkali. Etching tests made on iron carbide, chromium carbide, tungsten carbide, and high-speed steel constituent specimens in a rather strong hot alkaline potassium dichromate solution gave negative results in all cases. The addition of hydrogen peroxide to the hot solution did not aid any.

5. Potassium-Copper Cyanide Solution.-Thompson and Whitehead (61) found that a hot alkaline solution of potassiumcopper cyanide darkens iron carbide. This solution was tried out on the other constitutents covered in this investigation, even though it was recognized that the alkali was probably the predominating factor in the effects produced.

This solution was prepared in accordance with the method of Thompson and Whitehead. A 10 per cent potassium cyanide solution was run into a 10 per cent cupric nitrate solution until the precipitate, $\mathrm{Cu}(\mathrm{CN})_{2}$, changes to a yellowish-green colored cupriccuprous cyanide with evolution of cyanogen gas and dissolves in a small excess of potassium cyanide to form the double cyanide, $\mathrm{K}_{2} \mathrm{Cu}(\mathrm{CN})_{3}$. Equal parts of this solution and of a 50 per cent sodium hydroxide solution constituted the etching reagent.

When etched with the hot alkaline solution, chromium carbide, tungsten carbide, and vanadium carbide remained undarkened after five minutes' immersion, while iron carbide, iron tungstide, and highspeed steel constituent were readily darkened. Since the last three constituents are darkened by alkali, the etching effects of the double cyanide solution might be attributed to the alkali present. The tarnishing of the matrix, usually accompanying the use of strong alkaline solutions, however, was absent. No advantage was gained by using a 10 or 25 per cent sodium hydroxide solution instead of the 50 per cent solution (Table 2). The hot double cyanide solution containing no added alkali was next tried on the iron carbide and iron tungstide. The iron carbide lamellas (fig. 5) were darkened to a good brown and the carbide network to a light brown, after five minutes' immersion. The repolished specimen was etched for 10 minutes and the matrix found to be covered with a bluish-colored film, which obliterated the lamellas. The iron tungstide specimen was tarnished within 15 seconds after being immersed; the iron tungstide remained uncolored. These unsatisfactory effects seem to be due to the products of hydrolysis of the double cyanide. 
The results with the alkaline potassium-copper cyanide solution suggest strongly that the presence of some other compound in conjunction with a strong hydroxide solution does modify the tendency of the hydroxide toward tarnishing the specimen. The alkaline lead nitrate solution (equal volumes of a 10 per cent lead nitrate solution and a 50 per cent sodium hydroxide solution) used by Thompson and Whitehead for darkening cementite and referred to as Le Chatelier's reagent is of this kind. Etching tests in a hot solution showed chromium carbide, tungsten carbide, and vanadium carbide undarkened after 5 minutes' immersion, iron tungstide fully darkened within 5 minutes, and iron carbide in 5 to 10 minutes. No tarnish formed. A neutral 10 per cent lead nitrate solution under like conditions gave an acidic etching effect.

Attention should be called to the very satisfactory microstructures developed in plain carbon steels by the double cyanide solution containing 50 per cent hydroxide. The various forms of iron carbide found in these steels, lamellar, massive or proeutectoid, finely divided or sorbitic and agglomerized were revealed clean-cut against a bright, uncolored matrix. It would appear that fully as good, if not better, results can be obtained with this solution as with the usual hot alkaline sodium picrate solution and in an appreciably shorter period of time, though the poisonous character of the solution would militate against its general use. Comparative results obtained on an annealed 1.1 per cent carbon steel specimen are shown in Figure 5.

6. Recapitulation.-The results given above for oxidizing and nonoxidizing conditions show two distinct types of etching effects, (a) a chemical attack by the alkali directed solely to the constituent, and $(b)$ the oxidation of the constituent by nascent oxygen.

The constituents which showed effects of type $(a)$ are iron carbide, iron tungstide, and high-speed steel constituent. This last evidently contains a large percentage of iron tungstide and behaves in a very similar manner. The other constituents, chromium carbide, tungsten carbide, and vanadium carbide, remain undarkened. Iron tungstide is much more readily attacked than iron carbicle, as is well illustrated by Yatsevitch's reagent. At room temperature the former was strongly darkened in 1 minute, whereas the latter remains undarkened after 18 minutes' immersion. Since iron is known to become "passive" when immersed in an alkaline solution, it should be expected that the matrix of the specimens should remain unattacked; this was gencrally found true. Iron carbicle is slowly attacked by an alkali, as shown by etching carbon steels in hydroxide solutions ranging in concentration from 10 to 50 per cent; heating the solutions hastens the attack materially. No marked difference in the results 


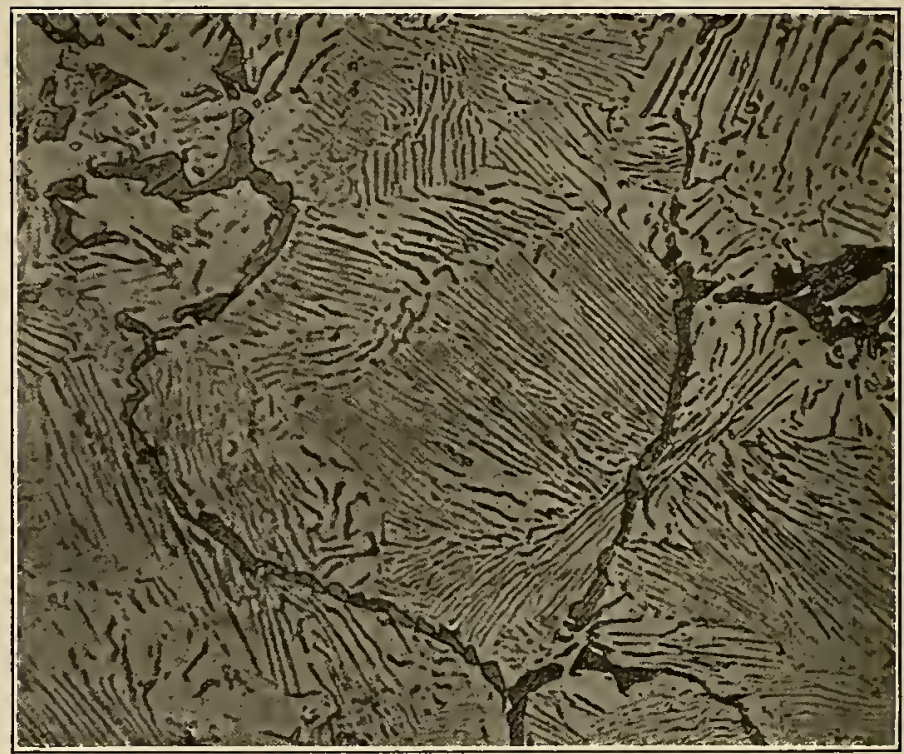

(a)

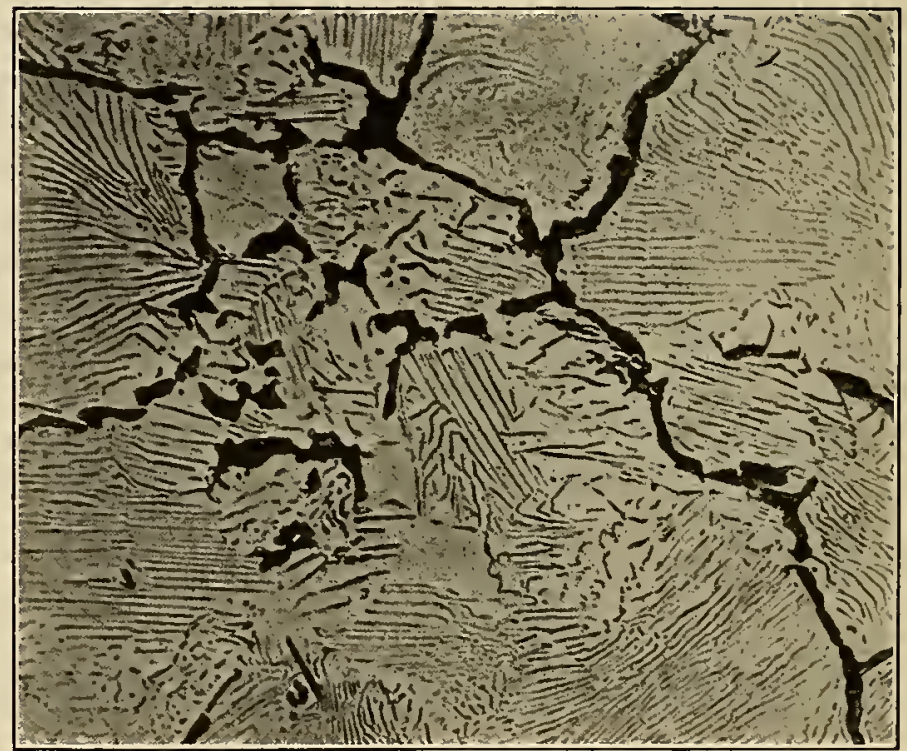

(b)

Fig. 5.-Microstructures of a 1.1 per cent carbon steel (5, A; Table 1) as developed by etching in hot alkaline solutions of potassium-copper cyonide and sodium picrate. $\times 500$

(a) Potassium-copper cyanide (1 minute) (b) Sodium picrate (10 minutes). 
was produced by the introduction of oxygen gas or of nascent oxygen through the decomposition of hydrogen peroxide. As a further check on this point, iron carbide and iron tungstide specimens $(5, \mathrm{~A}$ and $34 \mathrm{E}$, Table 1) were placed at the bottom of a 1-inch test tube filled with a hot 10 per cent sodium hydroxide solution to a depth of 4 inches. The tube was then surrounded by water which was kept boiling. The solution in the test tube remained quiescent, so there was no appreciable introduction of oxygen from the atmosphere. The iron carbide lamellas and iron tungstide particles were welldarkened after an immersion of 15 minutes and 1 minute, respectively.

In etching reagents, producing type $(a)$ effect, should be included the alkaline sodium picrate solution and similar solutions, such as alkaline sodium benzoate solution, alkaline potassium-copper cyanide solution, alkaline lead nitrate solution, etc. These reagents are really, in effect, a strong solution of alkali to which another chemical compound has been added whereby the tendency to tarnishing, possessed by the strong solution of alkali used alone, is overcome or strongly modified.

In type $(b)$ all the constituents were darkened by the nascent oxygen generated in the reaction between the alkali and certain salts, such as potassium ferricyanide and potassium permanganate. Nascent oxygen formed in this manner produces the etching effect, while that formed by the decomposition of hydrogen peroxide does not. The reason seems to be that the oxygen is generated in the layer of solution in intimate contact with the specimen in the former case, though not in the latter. Chromium carbide, tungsten carbide, iron tungstide, and high-speed steel constituent were, under these conditions, quickly darkened, while the iron carbide and vanadium carbicle responded somewhat more slowly. These solutions containing no alkali produced no darkening whatsoever with any of the constituents.

By using the immersion method of etching it should be possible to make the following distinctions between constituents in case more than one of them exist in the same alloy. A spot on the microsection is marked where these constituents are found present, preferably after etching with a reagent known to darken one constituent and not the others believed to be present. The marked field is photographed and the specimen reetched, without repolishing, in another reagent which is known to darken one of the remaining constituents and the same spot rephotographed. This is repeated with the third reagent, if necessary. This method has been termed "sequence etching." ?

7 Chem. and Met. Eng., 26, p. 778; Apr. 26, 1922.

$56832^{\circ}-25 \dagger-3$ 
To distinguish (a) iron carbide, iron tungstide, or high-speed stecl constituent from chromium carbide, tungsten carbide, or vanadium carbide, use either a hot 10 per cent solution of sodium or potassium hydroxide, alkaline sodium picrate, or alkaline potassium-copper cyanide. (b) Iron tungstide or high-speed steel constituent from iron carbide, chromium carbide, tungsten carbide, or vanadium carbide, use at room temperature either a 10 per cent solution of sodium or potassium hydroxide, or a mixture of 10 per cent sodium hydroxide solution and hydrogen peroxide. (c) Iron tungstide from all the other constituents mentioned, use a hot neutral sodium picrate solution. The iron tungstide is darkened within one minute; the other constituents remain undarkened for at least 10 minutes.

No way of distinguishing between chromium carbide, tungsten carbide, or vanadium carbide by means of any of the solutions in Table 2 was found. The form or other characteristics may often help; for example, tungsten carbide (WC) usually occurs as triangular or rectangular shaped particles. No sure distinction between any of the series of constituents was found with an oxidizing reagent, such as an alkaline solution of potassium ferricyanicle or of potassium permanganate.

\section{ELECTROLYTIC ETCHING TESTS}

The method of developing microstructures by means of electrolytic etching has yielded useful results in special cases. The specimen to be etched is made the anode (usually) of a "cell," the cathode being a platinum wire and the electrolyte the solution to be tested. The etching is brought about by the application of an external emf to the "cell." Sodium hydroxide has been found useful by Le Chatelier for determining phosphorus segregations in iron and steel by electrolytic etching and by Jeffries (38) for developing the microstructure of tungsten. It is also recommended for stellite, high-chromium and certain other alloys. ${ }^{8}$ In a recent article by Oertel and Pakulla (49) on high-speed cutting tools made from alloys similar to stellite, micrographs of these alloys, as etched electrolytically in a 10 per cont sodium hydroxide solution, are given. One constituent appears dark, another in half tone, and still another is not darkened. The authors imply the presence of structurally free chromium carbide. It would appear from the results obtained by the writer that the darkened constituent may be chromium earbide and also that the identification of the other two might be facilitated by the use of etching reagents known to darken certain constituents.

${ }^{8}$ Am. Soc. for Testing MIaterials, Standards, p. 1163; 1924. 
A series of electrolytic etching tests was undertaken for the study of alloy steel constituents. No alkaline or metallic salts of strong acids were tried, since an iron anode is known to assume an active condition in the presence of salts of strong acids, especially chlorides, and this activity continues as long as the current density does not reach a critical limit; under these conditions the matrix of the speeimen should be corroded in a general manner while the particles of the structurally free constituent would remain unattacked and standing out in strong relief.

The solutions used and results of these tests are presented in Table 3. The acid groups, all of which are "weak" acids, are arranged from left to right in the order as the degree of dissociation possessed by the acids representing these groups decrease. Since these tests were admittedly preliminary, no attempts were made to determine the current strength and solution coneentration needed to secure the most satisfactory results in the shortest time. Equivalent amounts of the acid, salt, or alkali should have been taken instead of percentage by weight if the strengths of the various solutions were to be put on a directly comparable basis; the percentage by weight method was chosen as a matter of conrenience, since the work was of an exploratory nature. An clectrolytic apparatus of the type used in chemical analytic work, operating on a 110-rolt, direct current line and with two 925-ohm slide resistances and an ammeter connected in series, was used. The resistance was so regulated to give current density from about 0.01 to 0.15 ampcre per square centimeter. The surface area of the microsection of the different specimens tested varied from about 1.5 to 6.5 square centimeters. No attempt has been made to indicate in Table 3 the current density employed; only the ammeter readings are given. 
TABLE 3.-Effect of electrolytic etching on constituents in alloy steels

Darkened, indicated by black-faced type; not darkened, by roman type. The strength of the various aqueous solutions were 10 per cent, by weight alkali, salt or acid (citric and acetic), unless otherwise stated. The specimen formed the anode, and a platinum gatuze eleetrode the cathode of the electric circuit. The current used (amp) and time of etching (min) in the individual tests are given below The eases where the darkening of the constituent was produced at a slow rate are indieated by' an asterisk $\left({ }^{*}\right)$

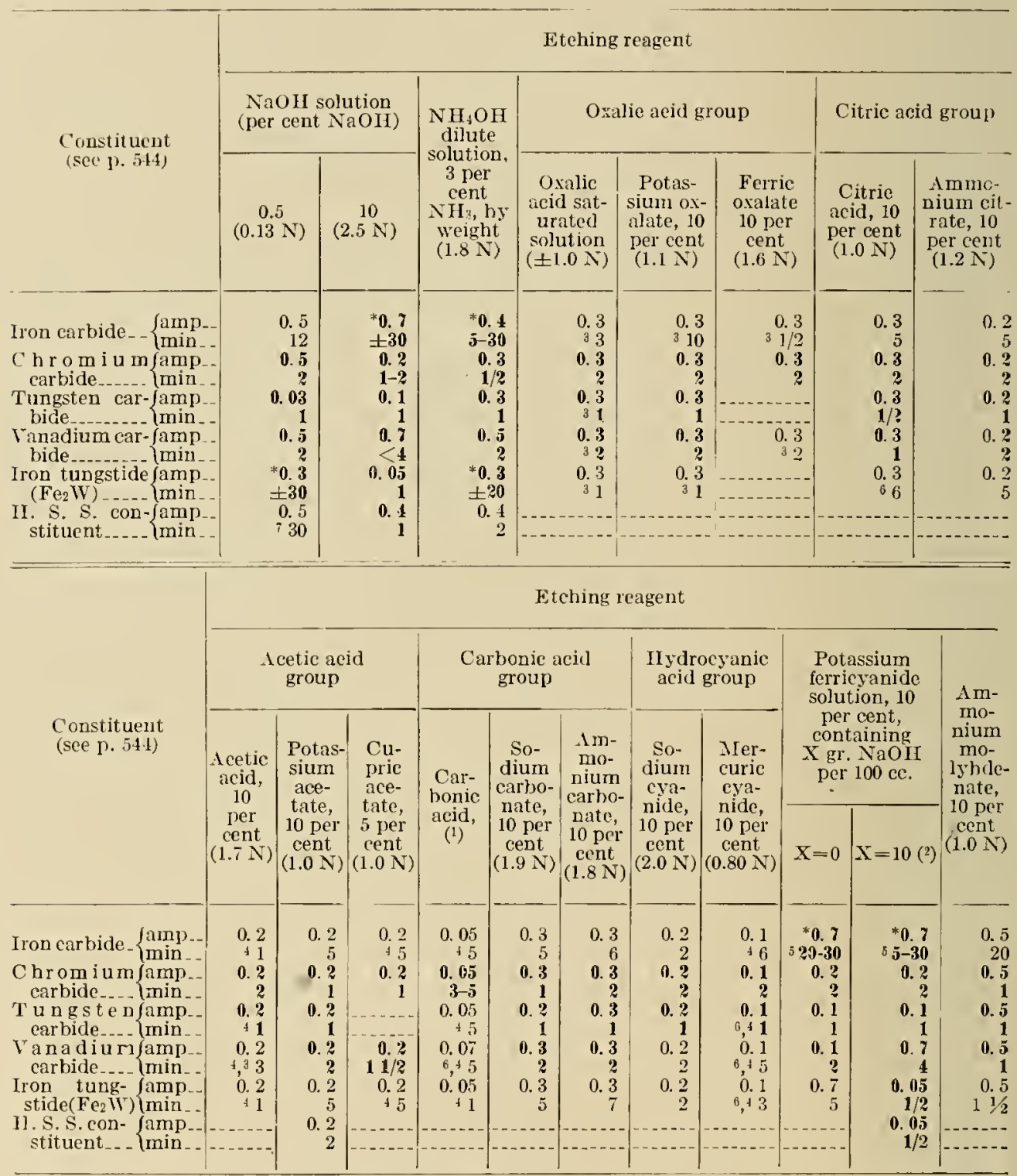

1 Saturated solution prepared by passing $\mathrm{CO}_{2}$ gas into a 750 ec flask nearly filled with tap water for 35 minutes.

2 Iurakami's reagent.

3 Matrix corroded in a quite general manner, though not deeply, in many cases.

- Matrix pitted in places.

3 The speed of darkening apparently depends on the physical condition, such as mass, of the iron carbide. For example, with specimen No. 5- $\Lambda$ (Table 1) and alkaline solution the carbide lamellas were darkened to a dark brown color in 5 minutes, while 20 minutes were required to darken portions of the network (proeutectoid cementite) to a light brown or gray-hlue eolor. With the same specimen and neutral solution, the lamellas were quite strongly darkened in 10 minutes while after 30 minutes both the lamellas and network had assumed a dark brown color; a bluish-colored film had formed over the microsection, according to the follorring equation, and it was easily removed by dipning the specimen into a strong NaOH solution. $\mathrm{Fe}+\mathrm{K}_{3} \mathrm{Fe}(\mathrm{CN})_{0}=\mathrm{Fe}_{3}\left(\mathrm{Fe}(\mathrm{CN})_{6}\right) . \quad \mathrm{Fe}_{3}\left(\mathrm{Fe}(\mathrm{CN})_{6}\right)+6 \mathrm{NaOII}+3 \mathrm{Fe}(\mathrm{OII})_{2}+2 \mathrm{Na}_{3} \mathrm{Fe}(\mathrm{CN})_{6}$.

${ }_{6}$ Matrix more or less tarnished.

i $\mathrm{A}$ few of the particles :npeared darkened after 30 Ininutes' etching, so the action produced in this case is evidently very slow. 
A glance orer Table 3 will show that, if we adopt a maximum time limit of trro or three minutes, the carbides of chromium, tungsten, and vanadium were, with a few exceptions, readily and similarly attacked by the various solutions, excepting those containing much free alkali, while the iron carbide, iron tungstide, and high-speed steel constituent remained unaffected. This last constituent was not tried out with most of the solutions, since it was found to behave in much the same manner as iron tungstide. Iron tungstide and the high-speed steel constituent, as well as the carbides of chromium, tungsten, and vanadium, were readily darkened by a 10 per cent sodium hydroxide solution. This should be expected by reason of the production of oxygen at the anode through the discharge of hydroxyl ions in alkaline solutions containing a considerable concentration of hydroxyl, and also of the ready solubility, in the case of iron tungstide and high-speed steel constituent, of the resulting tungstic oxide in alkalis to form a tungstate. It is not surprising that the iron tungstide should be slowly darkened and the high-speed steel remain unaffected by the 0.5 per cent $\mathrm{NaOH}$ and $\mathrm{NH}_{4} \mathrm{OH}$ solutions, for the concentration of hydroxyl ions in these solutions would be much smaller and the amount of oxygen liberated at the anode correspondingly reduced. The slow darkening of iron carbide etched electrolytically in a solution containing free alkali is in agreement with the results obtained in the immersion tests under oxidizing conditions (Table 2); this appears to be an inherent property of iron carbide. The lamellar form and small-sized particles of iron carbide are much more quickly darkened (about five minutes) than the larger particles, such as proeutectoid cementite and divorced pearlite (30 minutes or longer).

The positive and negative types of behavior shown by the alloy steel constituents when electrolytically etched in the various solutions other than those containing free alkali may be explained as follows: Oxygen isformed at the anode in two ways- (a) Through a secondary reaction ${ }^{9}$ between the acid formed in the first stages of the electrolysis and water, and $(b)$ by the discharge of hydroxyl ions. The formation of oxygen in the latter case should occur to a greater extent with the use of alkaline salts of weakly dissociated acids, since the alkali product of the electrolysis is strongly dissociated while the acid has a much lower degree of dissociation. The particles of the constituent thus exposed to the oxygen become oxidized and are more or less dissolved out, while the iron matrix is made passive. According to Evans, metals like iron, whose oxides are soluble in acid but not in alkali, tend to become active in acid solution and passive in alkalis, and metals like tungsten and molybdenum, whose principal oxides are soluble in alkalis, tend to become passive in acids but active in

${ }^{9}$ U. R. Evans, Metals and Metallic Compounds. E. Arnold \& Co., London, 1, p. 376; 1923. 
alkalis. With chromium, a different situation arises; it forms a high oxide $\left(\mathrm{CrO}_{3}\right)$ which is quite soluble in water. A chromium anode, dissolves quantitatively in a potassium chloride solution at $100^{\circ} \mathrm{C}$.', but in the same solution at room temperature it becomes passive, even with a very low current density, and no dissolution takes place. The oxygen accumulation on the anode surface evidently prevents the metal from passing into the ionic state. By applying a sufficiently high external emf (to quote Evans' words) "the chromium starts to dissolve once more, but now as the yellow (red) oxide $\mathrm{CrO}_{3}$ (or its hydrate, chromic acid, $\mathrm{H}_{2} \mathrm{CrO}_{4}$ ) ; evidently the dissolution will only commence when the anodic potential is so elevated that the oxygen concentration becomes sufficient to produce this high, endothermic oxide."

In short, chromium in the passive state dissolves to form the yellow chromic acid or a chromate. The presence of oxidizing agents or eren dissolved oxygen in the electrolyte favors the passive condition. In the writer's tests a strong yellow or yellowish-green film was formed over the polished surface of the specimen during the electrolytic etchings. This film was easily removed by washing, and the matrix appeared under the microscope still bright and smooth. It was also noticed that small streams of a yellow substance passed from the surface of the anode into the surrounding liquid where a yellow-brown solution was formed. The negative behavior shown by the iron carbide, iron tungstide, and high-speed steel constituent can not be so easily explained. It would appear that the concentration of the oxygen generated or of any alkali formed in the secondary stage of electrolysis was not strong enough to produce the darkening effect upon the iron tungstide (and high-speed steel constituent) within the periods of etching reported. (See Table 3 for iron tungstide in 0.5 per cent $\mathrm{NaOH}$ and $\mathrm{NH}_{4} \mathrm{OH}$.) It also seems possible that iron carbide and iron tungstide would tend to assume a passive state and resist attack under the weakly oxidizing or alkaline conditions because of the fact that iron forms a large proportion of their composition.

It would appear from a comparative study of the data in Table 3 for the three constituents, which gave positive darkening results, that chromium carbide and tungsten carbide are readily attacked, while ranadium carbide shows a less marked susceptibility to attack as evinced by the slower rate of darkening at an even higher current density in a solution containing free alkali (10 per cent $\mathrm{NaOH}$ and alkaline potassium ferricyanide) and by remaining unattacked when etched in certain solutions (ferric oxalate, acetic acid, sodiun cyanide, and mercuric cyanide). With the sodium cyanide solution, the matrix of the ranadium carbide specimen remained unattacked, so there could have been no possible directing of the corrosive attack to the matrix rather than to the carbide particles, as might appear 
to have been the case in the other above-named solutions. These three constituents showed a parallel behavior when immersed in hot alkaline potassium ferricyanide and potassium permanganate solutions (see Table 2). It was shown in Section VI, 1, that the darkening produced in these cases was due to the oxidation of the carbide particles by nascent oxygen and also that iron carbide, iron tungstide, and high-speed steel constituents are affected directly by the alkali itself.

In the cases where the electrolyte used was a weak acid, or a metallic salt of a weak acid, the matrix of the specimen was attacked to some extent by either a general corroding of the surface (oxalic acid and ferric oxalate) or a pitting or corroding of the matrix in localized spots (acetic acid, cupric acetate, carbonic acid, and mercuric cyanide). On the other hand, the matrix remained unattacked where alkaline salts or alkalis were used, evidently because the alkali present had rendered it passive. Two exceptions to this behavior in alkaline solutions were, however, met with-those of iron carbide and iron tungstide specimens in potassium oxalate. It would seem possible that in these two cases the oxalic acid formed from the alkaline salt solution was strong enough, because of its possessing a quite strong degree of dissociation, to neutralize the passivity-forming effect of the alkali, and also that the matrix offered less resistance to the corroding influence of the free acid as long as these two constituents had not become oxidized and consequently offered a greater resistance to the action of the acid. The matrix in the chromium carbide specimens remained unaffected in all cases. This may be attributed to the corrosion-resisting properties of the chromium-iron solid solution, a quality so well made use of in "stainless steels."

According to the results of these tests the electrolytic etching method should furnish a reliable and easily obtained distinction, in the manner indicated below, between the various constituents of alloy steels, particularly in cases where two or more constituents may be present. All cases in Table 3 where the matrix was corroded or pitted by the etching solution have not been considered in the following summary.

To distinguish (a) chromium carbide, tungsten carbide, or vanadium carbide from iron carbide, iron tungstide, or high-speed steel constituents, an alkaline salt of any of the weakly dissociated acids is preferably used as the electrolyte. (b) Chromium carbide from ranadium carbide, use a sodium cyanide solution. Distinction may possibly be made with either a 10 per cent sodium (or potassium) hydroxide solution or alkaline potassium ferricyanide solution prorided a current just strong enough (about $0.03-0.05 \mathrm{amp} / \mathrm{cm}^{2}$ ) to darken within two minutes the chromium carbide but not the 
vanadium carbide is used. (c) Tungsten carbide from vanadium carbide, use same procedure as $(b)$. ( $d$ ) Iron carbide from iron tungstide or high-speed steel constituent, use a 10 per cent sodium (or potassium) hydroxide and a weak current (about $0.02 \mathrm{amp} / \mathrm{cm}^{2}$ ) for one minute. Iron carbide should remain undarkened.

Since both chromium carbide and tungsten carbide are readily attacked and in a similar manner by the various solutions tried, no distinction between these two constituents by the electrolytic etching method is available. No sharp distinction by electrolytic etching between iron tungstide and high-speed steel constituent was obtained.

\section{HEAT-TINTING TESTS}

It is well known that the color of an oxide film on a metallic surface is dependent on the phenomenon of interference of light which, in turn, is related to the thickness of the film. Where more than one constituent is present in a microsection the different rates of oxidation of these constituents should produce a difference in the thickness of the film, and consequently in the color, formed. Stead first developed this delicate method of metallographic analysis, an example being the determination of the distribution of phosphorus in steel and cast iron.

Iron carbide is known to become red-brown at $280^{\circ} \mathrm{C}$. Gill and Bowman (21) tried the heat-tinting method on high-speed steels and reported the high-speed steel constituent to remain undarkened. It was thought worth while to try this method on the different constituents covered in this investigation.

The specimens, very lightly etched with alcoholic picric acid solution, were floated on a molten tin bath, previously heated to a little over $300^{\circ} \mathrm{C}$. to allow for the cooling produced by the insertion of the cold specimen. The specimens were kept at approximately $300^{\circ} \mathrm{C}$. generally for 30 minutes and allowed to cool in the air after being taken off. The results obtained are given in Table 4 . The minimum temperature reported was, in most cases, recorded about one minute after the insertion of the specimen.

Iron carbide was the only constituent darkened by this treatment. The behavior of the matrix in the various types of alloy steels is of some interest. Generally speaking, under the conditions of these experiments, the color assumed by the matrix of chromium steels was brown, that of high-speed steels reddish-brown or brown, that of tungsten-iron-carbon alloys blue (brown-red to blue in the two cases where iron carbide was present in appreciable quantity), and that of the vanadium-iron-carbon alloy blue. It would seem that the presence of chromium in solid solution with iron has a different influence on the rate of oxidation produced than that of tungsten or vanadium has. 


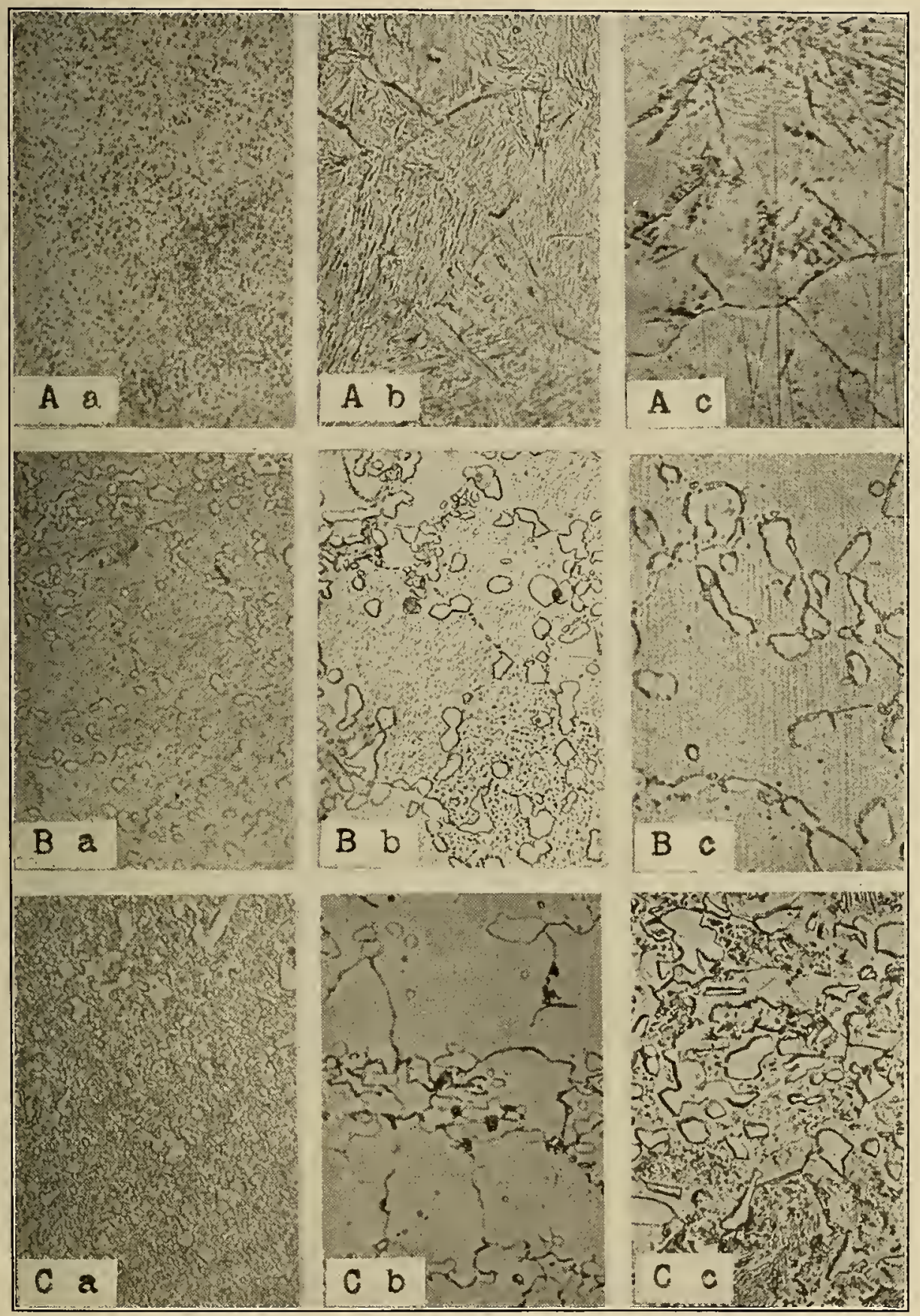

FIG. 6.-Microstructures of three chromium steels, containing different percentages of chromium and carbon, and in different heat-treated conditions. $\times 500$

Series A: 8.2 per cent $C r$. and 0.3 per cent C. (12, Table 1).

Series B: 22.4 per cent $C r$. and 0.3 per cent C. (24, Table 1$)$.

Series C: 15.0 per cent $\mathrm{Cr}$. and 1.1 per cent C. (19, Table 1$)$.

Heat treatment $a$ : Annealed for a short time at $900^{\circ} \mathrm{C}$. and furnace cooled.

Heat treatment $b$ : l feated four hours at $1,100^{\circ} \mathrm{C}$. and quenehed in oil.

Heat treatment $c$ : Heated four hours at $1,100^{\circ} \mathrm{C}$, and very slowly cooled in furnace.

Etched with 2 per cent alcoholic $1 \mathrm{INO}_{3}$. 
TABLE 4.-Effect of heat-tinting on the various alloy steel constituents

\begin{tabular}{|c|c|c|c|c|c|}
\hline \multirow{2}{*}{$\begin{array}{c}\text { Material } \\
\text { number } \\
\text { (Table 1) }\end{array}$} & \multirow{2}{*}{$\begin{array}{l}\text { Constituent present } \\
\text { (see p. 544) }\end{array}$} & \multicolumn{2}{|c|}{ Color produced } & \multirow{2}{*}{$\begin{array}{c}\text { Temper- } \\
\text { ature } \\
\text { of tin } \\
\text { bath }\end{array}$} & \multirow{2}{*}{$\begin{array}{l}\text { Time } \\
\text { immersed }\end{array}$} \\
\hline & & Constituent & Matrix & & \\
\hline & & & & $\circ C$ & Minutes \\
\hline $52-\mathrm{F}^{-}$ & Iron carbide & $\begin{array}{l}\text { Red-brown } \\
\text { do }\end{array}$ & Blue do....- & $\begin{array}{l}290-305 \\
260-308\end{array}$ & 30 \\
\hline $13-\mathrm{C}$ & Chromium carbide & None.... & Red-brown & $266-318$ & 31 \\
\hline $19-F_{-}$ & $\ldots$ do & ....do $\mathrm{do}_{-\ldots}$ & Brown & $270-314$ & 30 \\
\hline $20-\mathrm{C}$ & $\ldots$..... do..... & .....do... & ..... do & $277-310$ & 32 \\
\hline $23-\mathrm{C}_{-}$ & do & .... do & do & $285-300$ & 29 \\
\hline $54-\mathrm{I}_{-}$ & Vanadium carbide. & --do_- & Deep blue.. & $260-308$ & \\
\hline $27-E_{-}$ & $\left\{\begin{array}{l}\text { Tungsten carbide. } \\
\text { Iron tungstide }\end{array}\right.$ & 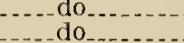 & Blue...... & $288-300$ & 30 \\
\hline & Iron carbide (sorbitic) & Dark & & & \\
\hline $31-1$ & $\{$ Iron tungstide....-- & None........ & Brown-red to blue.. & $258-310$ & 30 \\
\hline $32-I_{-}$ & fron tungstide.- & None & & $258-310$ & 30 \\
\hline & \{ron carbide & Red-brown & $-. . . \mathrm{d} 0 . . . .$. & & \\
\hline $\begin{array}{l}33-\mathrm{E}_{-} \\
34-\mathrm{E}\end{array}$ & Iron tungstide. & None & Deep blue.. & $302-310$ & 30 \\
\hline $\begin{array}{l}34-\mathrm{E} \\
34-\mathrm{C}\end{array}$ & ... do & -..do_. & & $302-310$ & 30 \\
\hline $\begin{array}{l}34-\mathrm{C}_{-} \\
36-\mathrm{N} .\end{array}$ & - do & -..-do-_ & Light blue & $270-300$ & 21 \\
\hline $\begin{array}{l}36-\mathrm{N}- \\
37-\mathrm{N}\end{array}$ & II. S. S. constituent ${ }^{2}$. & -..do_. & Reddish-brown_ & $258-310$ & 30 \\
\hline $\begin{array}{l}37-\mathrm{N}- \\
38-\mathrm{N}\end{array}$ & - - do. ${ }^{2}-\ldots-1-1$ & -...do_. & ..... do & $258-310$ & 30 \\
\hline $38-\mathrm{N}-$ & -..-do. ${ }^{2}-$ & -...do_.. & .....do & $275-300$ & 55 \\
\hline $39-0-$ & $\ldots$ do..$_{2}^{2}$ & -._do_-. & ............... & $275-300$ & 55 \\
\hline $40-\mathrm{O}$ & _. & ..._do... & do & $275-300$ & 55 \\
\hline $41-F$ & ......do.... & ...-_do_.. & Blue................. & 291-302 & 30 \\
\hline $41-\mathbf{E}$. & ......do_. & ...do.. & Brown with blue center & $291-302$ & 30 \\
\hline 42-B- & ......do...... & ....do_.. & Blue & $270-314$ & 30 \\
\hline $42-E_{-}$ & ......do.... & do & Brown & $288-300$ & 30 \\
\hline
\end{tabular}

1 There were distributed throughout the microstructure of this specimen, in addition to a large amount of lamellar pearlite, irregular-shaped small particles which remained undarkened. These particles responded, in immersion tests made witb alkaline sodium picrate solution and sodium hydroxide-hydrogen peroxide solution, to the identifieation test for iron carbide (undarkened in latter reagent) and not for iron peroxide solution, to the identifieation test for iron carbide (undarkened in latter reagent) and not for iron
tungstide (darkened in both reagents). The failure of these particles to respond to the heat-tinting test may be due to the presence in the alloy of 0.3 per cent vanadium and 3 per cent tungsten, one or both of which may bave entered and thus modified the composition of a portion of the iron carbide, represented by these particles.

2 In these fused specimens there was found present, besides the high-speed steel constituent occurring as a rib-shaped eutectic (characteristic of bigh-speed steels in the cast condition) and as globular or irregular-shaped particles, numerous strand-like or irregular-shaped particles of an unknown constituent. These particles, which stood out in markedly greater relief than the rest of the microsection, remained undarkened and possessed a distinctly different tone (yellowish) from that (whitish) of the high-speed steel constituent.

\section{MICROGRAPHIC ILLUSTRATIONS OF ETCHING EFFECTS PRODUCED}

The micrographs (figs. 6 to 16 , inclusive) will illustrate $(a)$ some forms of the constituents, excepting iron carbide, on which the abovedescribed etching tests were made, (b) the comparative behavior of some of the constituents toward certain etching reagents, and $(c)$ a few examples of the practical application of the "sequence etching" method.

Figure 6, series $A$ and $B$, shows the increase in quantity of free chromium carbide as produced by raising the chromium content in a steel of constant carbon content. An increase in the quantity of carbide, as obtained by raising the carbon content of a steel containing a lower, though relatively high, percentage of cluromium, is clearly indicated in Figure 6, series B and $C$. The series A steel contained low enough chromium and carbon that it retained in the quenched condition the whole of the carbide in solid solution. According to Figure 1, the series A steel lies well to the left of the solu- 


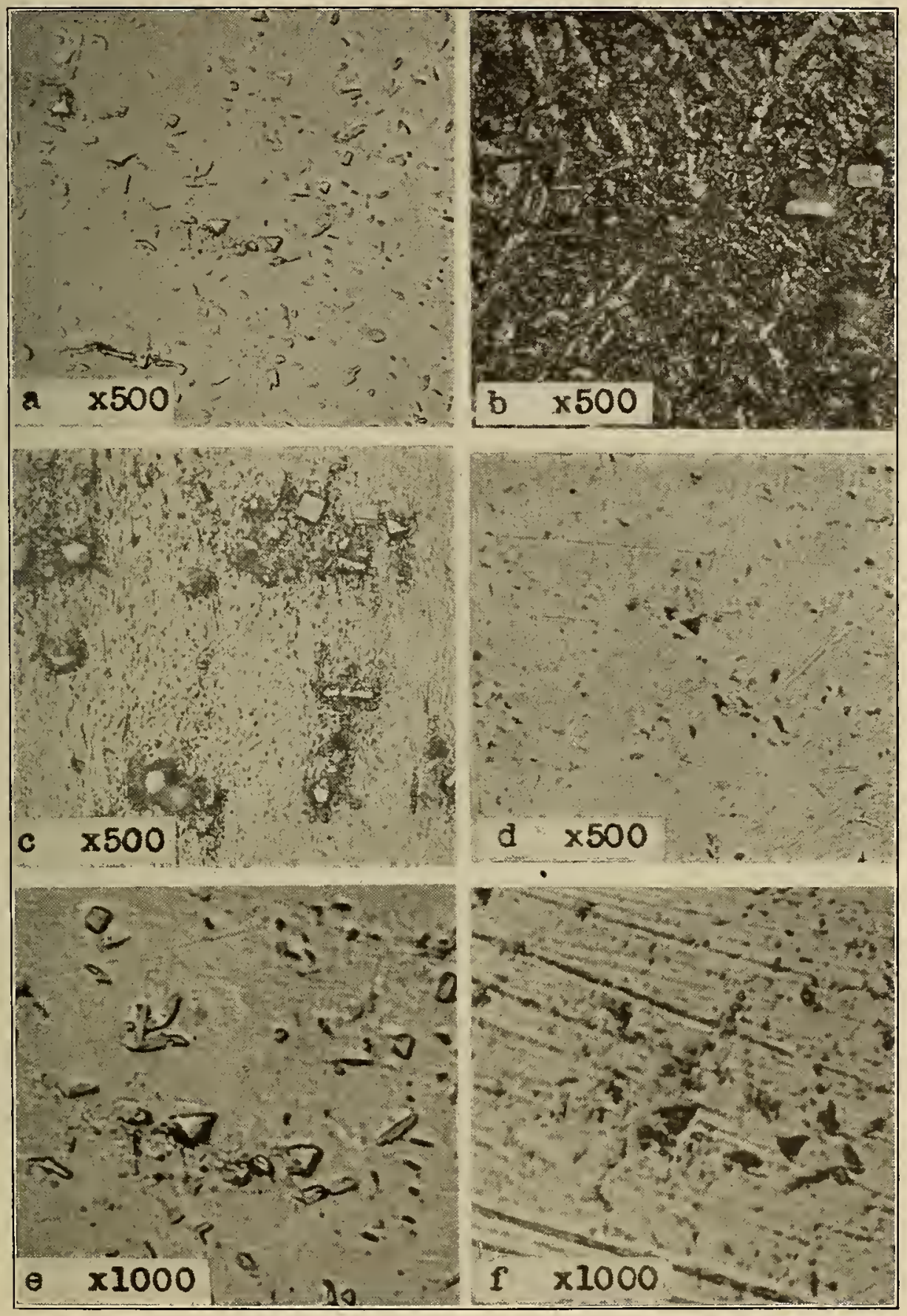

FIG. 7.-Microstructures of a tungsten steel, containing 5.2 per cent tungsten and 1.2 per cent carbon (27, Table 1)

$a, d, c$, and $f$ : Annealed for a short time at $900^{\circ} \mathrm{C}$. and furnace cooled.

$b$ : Heated four hours at $\pm 1,100^{\circ} \mathrm{C}$. and quenched in oil.

$c$ : Heated four hours at $\pm 1,100^{\circ} \mathrm{C}$., very slowly cooled in furnace.

$a, c$, and $e$ not etched; $b$ etched with 10 per cent alcoholic $\mathrm{HNO}_{3}, d$ with hot alkaline potassium ferricyanide solution, and $f$ with hot alkaline potassium permanganate solution; $a, e$, and $f$ taken at same spot in microsection.

Magniflcation: $\times 500$ and $\times 1,000$, as indicated above. 
bility line, and consequently should show no eutectic, series B steel very near the line and show some eutectic, and scries $\mathrm{C}$ steel well to the right and show an appreciably greater quantity of eutectic; the micrograplis for the quenched series appears to bear this out. The extremcly slow cooling from the high temperatures had permitted the carbide to coalesce into larger masses and also allowed a quantity of carbide, which would have remained in solution under ordinary conditions of cooling, to precipitate. Figure $8, e$, shows how cleanly the chromium carbide particles are brought out by etching electrolytically in a weak $(1.8 \mathrm{~N})$ ammonium hydroxide solution.

The very small size of the tungsten carbide particles, as found in a commercial tungsten steel containing 5 per cent tungsten and 1 per cent carbon as received from the mill, is illustrated by Figure 7, a, and $e$. Figure $7, c$, and $d$, suggests that heating at a high temperature for several hours coalesced the carbide particles into larger masses. A test was made to check Ozawa's statement (see p. 534) that the cementite-iron tungstide solid solution decomposes at a high temperature with the formation of angular-shaped crystals of tungsten carbide (WC) by heating specimens of two iron-tungstencarbon alloys (31 and 32, Table 1; also see Figures 10, $a$, and 16, $c$, and $d$ ) at 1,100 to $1,190^{\circ} \mathrm{C}$. for $31 / 2$ hours. One specimen of each alloy was quenched in oil, and another allowed to cool with the furnace, which was of the gas and air type used for heat-treating high-speed steels. A considerable number of angular particles of WC were found present in both the quenched and annealed specimens of the higher carbon alloy (No. 31) and none in specimens from the lower carbon alloy (No. 32). Before this heat treatment nothing but iron tungstide and cementite was to be seen in the microsection of both alloys; after the heating no iron tungstide was found in the portions of the higher carbon alloy specimen where the $\mathrm{WC}$ particles had formed. A specimen of the higher carbon alloy heated at this high temperature for one hour and quenched in oil developed the WC crystals in a similar manner.

It would appear that there is a definite carbon limit, depending on the tungsten content, below which no WC particles will be formed by this heat treatment. The tungsten carbide particles are shown in Figure $7, d$ and $f$, to have been darkened (or eaten out) by being etched in either a hot alkaline solution of potassium ferricyanide or potassium permanganate. Etching electrolytically in either a weak sodium hydroxide or ammonium hydroxide solution produces very similar darkening effects (fig. $8, a, b, c$, and $d$ ). In these last four micrographs irregular uncolored masses, in many of which are embedded the darkened tungsten carbide particles, will be noticed. 


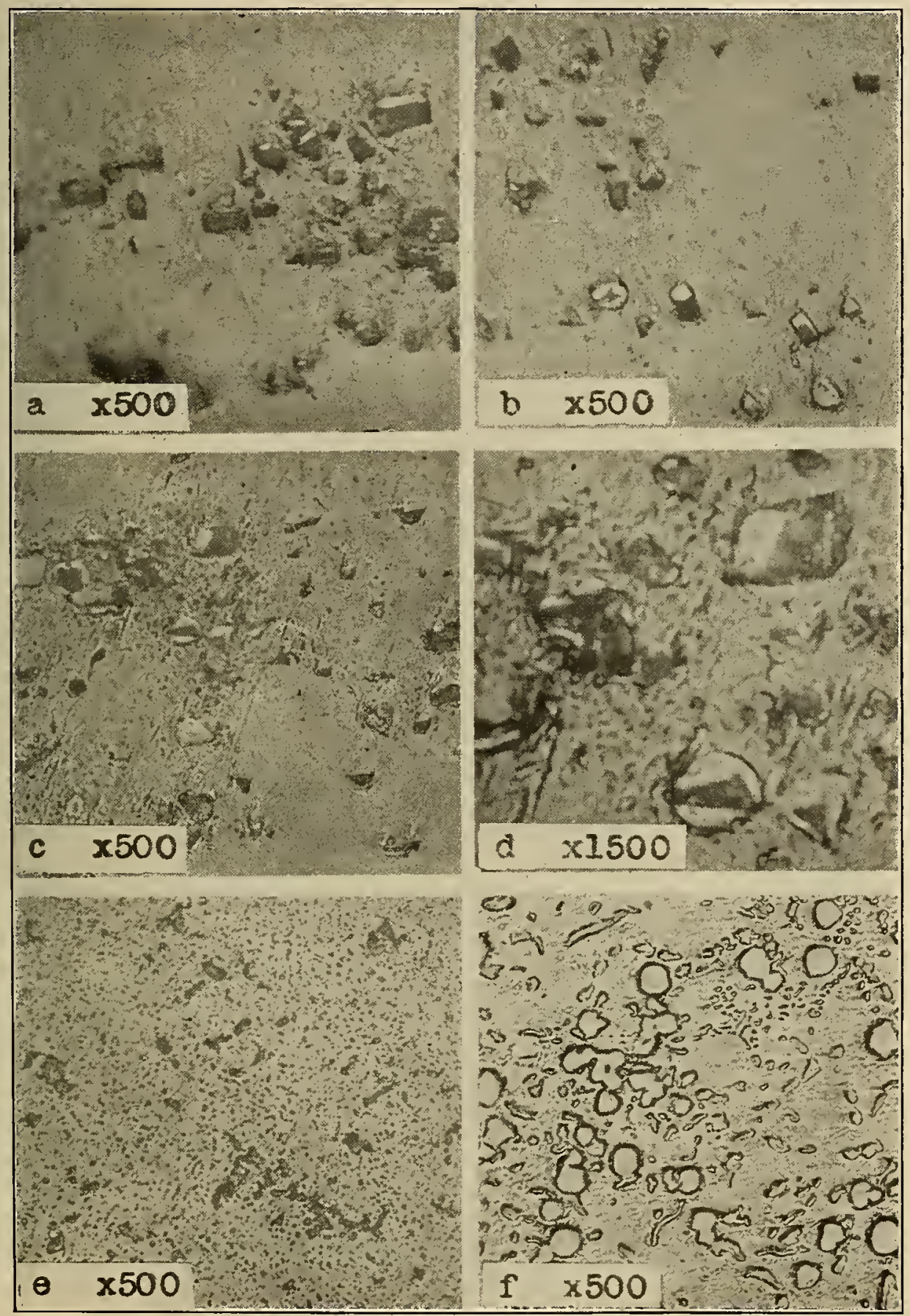

Fig. 8.-Microstructures of a tungsten steel (27, E; Table 1) and a chromium steel $(19, F)$, showing the tungsten carbide and chromium carbide particles as darkened by etching electrolytically, and of a vanadium-iron-carbon alloy $(54, I)$, showing the particles of vanadium carbide

$a, b, c$, and $d$, tungsten steel; $e$, chromium steel; $f$, vanadium-iron-carbon alloy.

$a$ and $b$ etched with 1 per cent $\mathrm{NaOH}$ solution; $c$, $d$, and $e$ with $\mathrm{NH}_{4} \mathrm{OH}$ solution (containing 3 per cent $\left.\mathrm{NH}_{3}\right) ; f$, not etched; $c$ and $d$ taken at same sopt in microsection.

Magnifleation: $\times 500$ and $\times 1,500$, as indicated above. 
These masses were observed only in the specimens of the tungsten steel or iron-tungsten-carbon alloy containing over 1 per cent carbon that had been heated at a high temperature for several hours and slowly cooled. They remained undarkened when etched with various reagents covered in this investigation, and consequently could not be identified. It hardly seems likely that they could be metallic tungsten or a tungsten-iron compound, particularly as crystals of tungsten carbide were found embedded therein or in close contact with them. It may be of interest to note in this connection an article by Andrews and Dushman (3) on the rate of diffusion of carbon through a tungsten carbide $\left(W_{2} \mathrm{C}\right)$ shell to a metallic tungsten core of tungsten lamp filament and vice versa through a tungsten shell (that had become decarburized) from the $\mathrm{W}_{2} \mathrm{C}$ core.

Figure $8, f$, is typical of the structure of ranadium-iron-carbon alloys (54 and 55, Table 1 ); the large and small particles of ranadium carbide $\left(\mathrm{V}_{4} \mathrm{C}_{3}\right)$ are quite thickly and uniformly scattered through a rather soft matrix.

Since the carbon content in the tungsten-iron alloy, illustrated in Figure 9, is rery low, the constituent must be pure iron tungstide $\left(\mathrm{Fe}_{2} \mathrm{~W}\right)$ which precipitated during the cooling from casting temperature (fig. 2). Figure 9, $d$ and $e$, illustrates the darkening produced by etching in a solution containing a free alkali. The etching time for $d$ was 45 seconds and that for $e 15$ seconds; there is little choice to be had between the two solutions referred to.

Figure 10, a, offers a striking example of the incomplete information one would get by relying on etching with an acid alone in cases where there is more than one structurally free constituent present. By etching a microsection, already etched with alcoholic picric acid solution but not repolished, with a solution known to darken iron tungstide, the presence of iron tungstide embedded for the most part in another constituent is clearly revealed (fig. 10, $b$ ). The assumption, based on a consideration of the composition, that the remaining undarkened constituent is cementite is confirmed by etching with sodium picrate (fig. 10,c). Figure 10, $d$ and $e$, illustrates the same point. Figure 10, $b$, appears to confirm Ozawa's (50) statement that the iron tungstide has a greater crystallizing power than the austenite and consequently assumes a dendritic form.

Figure 11, $a$ and $b$, show that, according to the etching results obtained as indicated, no particles of cementite, per se, were present in the microsection of a chrome-vanadium tool steel (51, Table 1). 


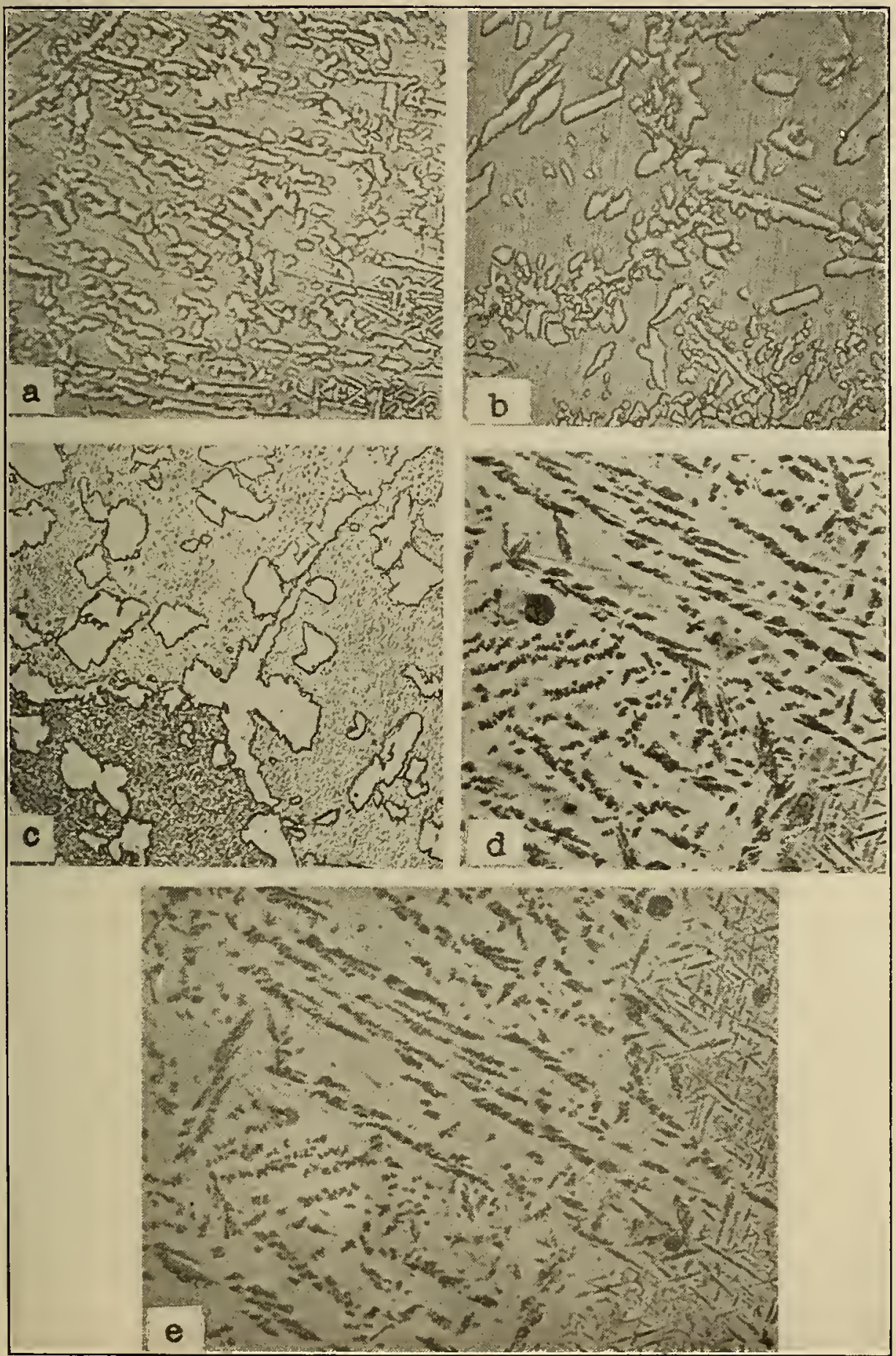

Frg. 9.-Microstructures of a tungsten-iron alloy containing 25.5 per cent tungsten and 0.05 per cent carbon $(34$, Table 1$) . \times 500$

$a, d$, and $\ell$, in the as-cast condition .

$b$, heated four hours at $\pm 1,100^{\circ} \mathrm{C}$. and quenched in oil.

$c$, heated four hours at $\pm 1,100^{\circ} \mathrm{C}$. and very slowly cooled in furnace.

$a, b$, and $c$ etched with 2 per cent alcoholic $\mathrm{HNO}_{3}, d$ with hot alkaline sodum pierate solution (Kourbatoff's reagent), and $e$ with 10 per cent $\mathrm{NaOH}-\mathrm{H}_{2} \mathrm{O}_{2}$ mixture (Yatsevitch's reagent). 


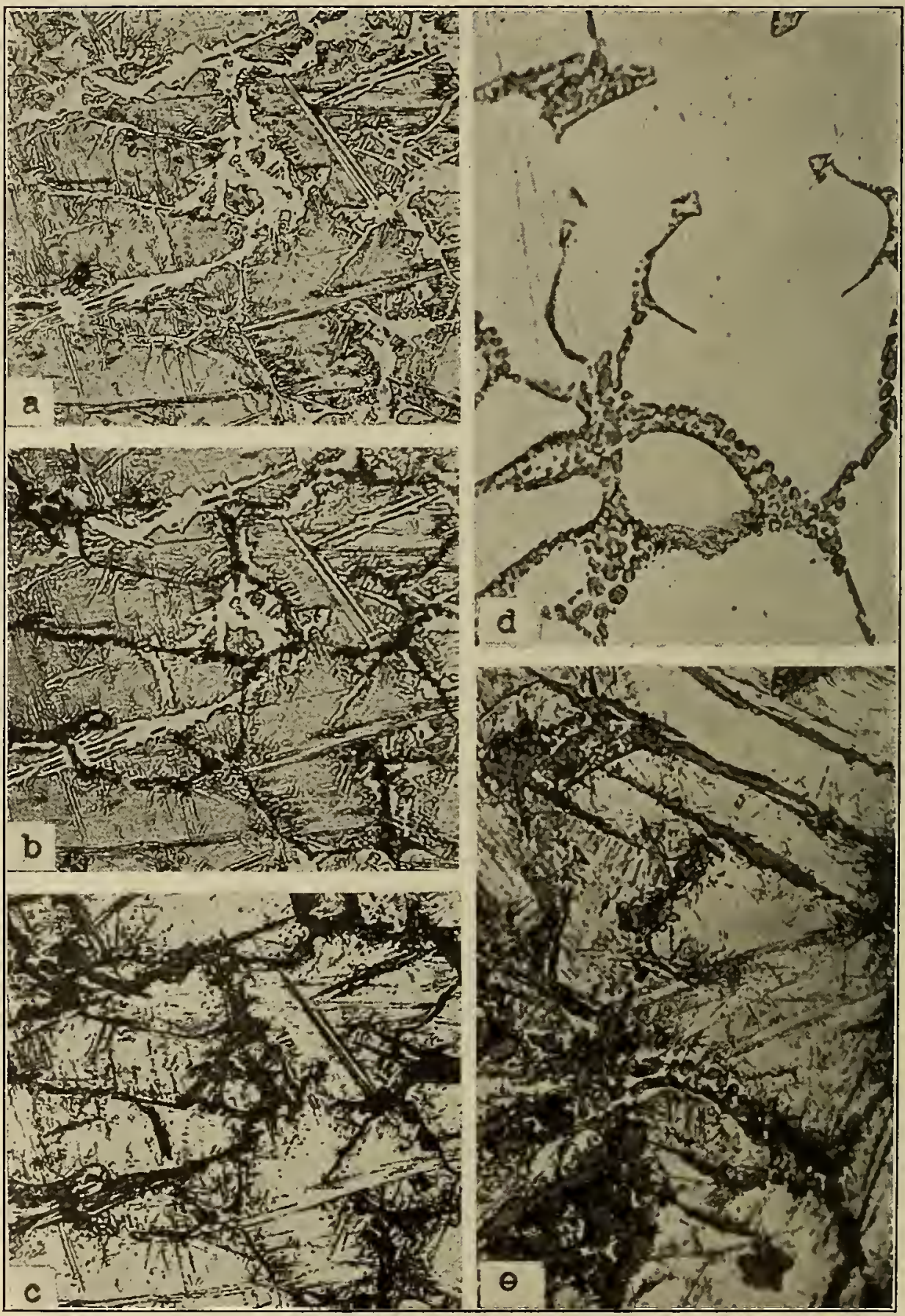

FIG. 10.-Microstructures of a tungsten-iron-carbon alloy, containing 11.7 pcr cent $\mathrm{W}$ and $1.6 \mathrm{per}$ cent $C$. (31, Table 1-in the as-cast condition), ctched by the sequence method to bring out differentially the two structurally free constituents found present. $\times 500$

$a, b$, and $c$ were taken at the same spot in one portion of microsection, $d$ and $e$ at the same spot in another portion of the same microsection. The two sets of etchings were made at different times after the specimens had been repolished. For each set of etchings the specimen was not repolished bet ween etchings.

$a$, etched with 5 per cent alcoholic picric acid, $b$ and $d$ with 10 per cent $\mathrm{NaOH} \rightarrow \mathrm{H}_{2} \mathrm{O}_{2}$ mixture, and $c$ and $c$ with hot sodium picrate solution. The darkened constituent in $b$ and $d$ is iron tungstide and that in $c$ and $c$ cementite (and iron tungstide). 


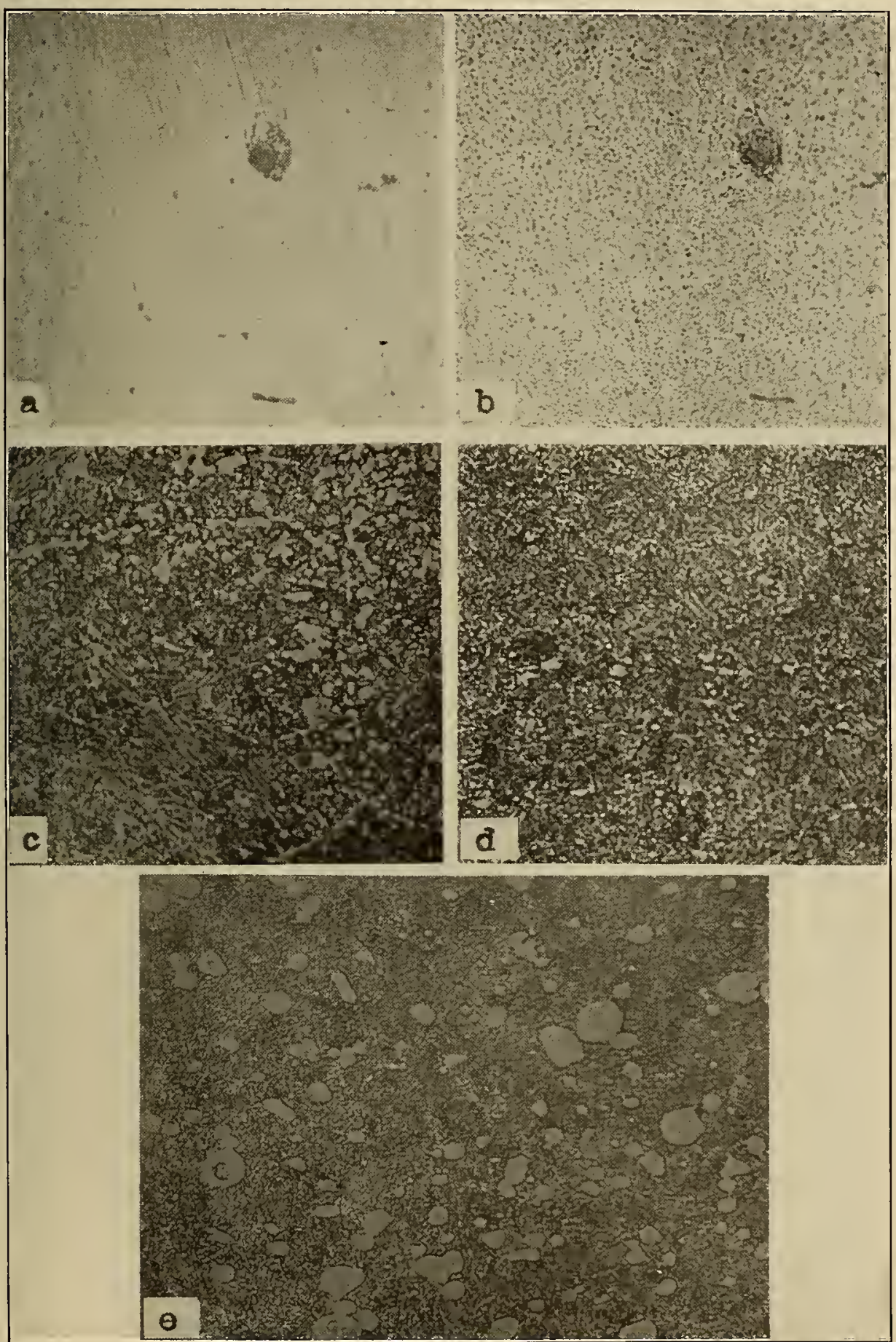

FIG. 11.- Microstructures of three commercial alloy steels and a high tungstenlow vanadium high-speed steel showing the form and distribution of the structurally free constituents found present. $\times 500$

$a$ and $b$, a chrome-vanadium tool steel (51, Table 1); c, a tungsten-vanadium tool steel (52); $d$, a magnet steel (28); and $e$, a regular grade of high-speed steel $(41, \mathrm{~F})$.

$a$, etched with hot sodium picrate solution; $b$, with hot alkaline potassium ferricyanide solution-note the darkened chromium carbide particles; $c$, $d$, and $e$, with 2 per cent alcoholic $\mathrm{HNO}_{3} . \quad a$ and $b$ were taken at the same spot, and the microsection was not repolished between the etchings.

$$
56832^{\circ}-25 \dagger-4
$$


Figure 11, c, shows the microstructure, as developed by etching with nitric acid, of a tungsten-vanadium tool steel (52, Table 1) containing about 1.3 per cent carbon, 3 per cent tungsten, 0.25 per cent vanadium, and 0.2 per cent chromium. The question might be asked as to what rôle the 3 per cent of tungsten would assume in the structure of this alloy containing a high percentage of carbon. Etching with sodium hydroxide-hydrogen peroxide mixture failed to show the presence of iron tungstide, other than a distribution throughout the matrix of very fine dark specks (iron tungstide?). The particles shown in Figure 11, $c$, were determined to be apparently cementite by sodium picrate etching, although in the heat-tinting tests they remained uncolored as contrasted with the darkening to a red-brown color of the cementite plates of the lamellar pearlite present, together with sorbitic pearlite, in the matrix. It would seem that these carbide particles contained some other element besides iron in sufficient amount to prevent their assuming in heat tinting the red-brown color characteristic of cementite, but not their becoming darkened by sodium picrate. The evidence obtained offers no suggestion as to the identity of this alloying element, other than it is possibly tungsten, since iron tungstide is readily darkened by sodium picrate while chromium carbide and vanadium carbide are not, and the existence of a cementite-iron tungstide compound in iron-tungsten-carbon alloys has been pointed out by Ozawa (50). On the other hand, in the microstructure of specimens of a magnet steel containing about 6 per cent tungsten and 0.7 per cent carbon (28, Table 1), there were found present a moderate quantity of iron tungstide particles distributed in a matrix composed of sorbitic and a little lamellar pearlite (fig. 11,d). Apparently, the tungsten content in the latter steel was sufficient in quantity, together with the amount of carbon present, for the formation of iron tungstide, which was not combined or mixed up with the cementite, as seems to be the case where the carbon content is high enough to form proeutectoid cementite.

In some electrolytic etching tests of specimens of commercial high-speed steels it was noticed that extremely small particles of a substance were brought out as darkened specks (fig. 12), while the globules of the constituent usually found in high-speed steels in the forged and heat-treated condition remained undarkened. The presence of an additional constituent, represented by these speclis, would certainly not have been rerealed in etching the section with an acid solution (see fig. 11,e). An examination of specimens of other high-speed steels, some of which had been partially or completely fused by excessive heating or intentional remelting, showed that there was present besides the usual constituent another constituent possessing greater hardness and different characteristics 


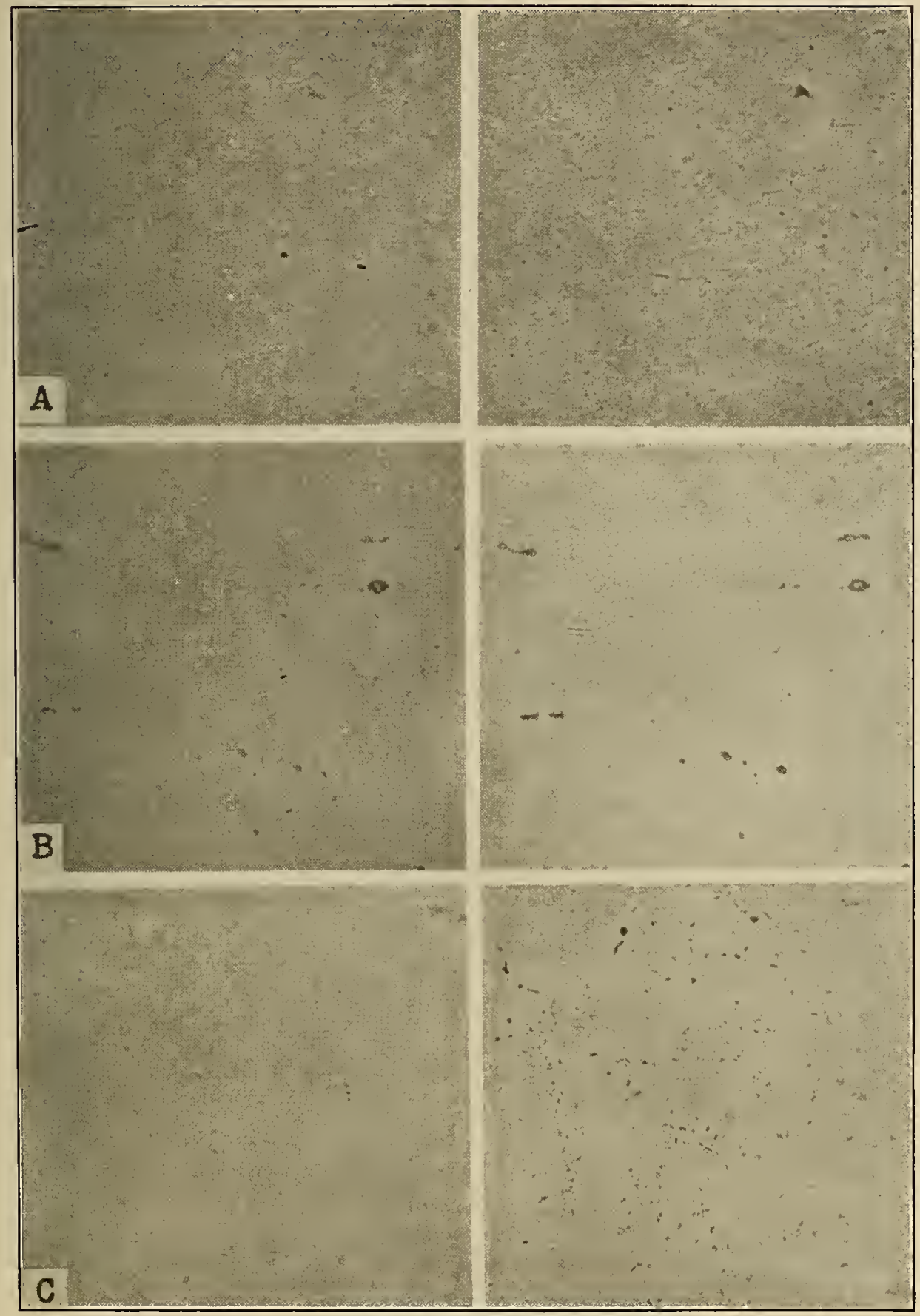

Unetched.

Etched.

FIG. 12.-Microstructure of a high tungsten-low vanadium high-speed steel (41, Table 1), showing the presence and obsence of very small sized particles of an unidentified constituent. $\times 500$

$A$, as received from the mill.

$B$, heated four hours at $1,100^{\circ} \mathrm{C}$. and quenched in oil.

$C$, heated four hours at $1,100^{\circ} \mathrm{C}$. and very slowly cooler in furnace.

Etched electrolytically in 10 per cent jotassium acetate solution. Each pair of micrographs were taken at the same spot in the microsection. 
(see figs. 13, 14, and 16). 'This constituent, designated as the "hard constituent," occurred in larger and more compact masses in the fused specimens; its behavior toward various etching reagents was similar to that of the very small specks noted in Figure 12 and different from that of the usual high-speed steel constituent (globules or rib-shaped eutectic). The nature of this "hard constituent" is not known; it may be added that it behaves toward certain etching reagents in a similar manner as chromium carbide and vanadium carbide do. Figure 16 will illustrate the presence, as revealed by the sequence etching method, in a fused specimen of a low tungstenhigh vanadium high-speed steel of three different structurally free constituents-(a) "hard constituent," (b) high-speed steel constituent, and (c) cementite (as judged from its behavior toward sodium picrate).

Figure 16 shows the heat-tinted structures of various materials. Attention should be called to Figure 15, $c$ and $d$, where the cementite is shown in half tones as contrasted with the uncolored iron tungstide particles; in the latter figure the cementite particles are scattered along the dark zones lying between the rib-shaped eutectic masses and the speckled-like oval areas, which appear to be eutectoid iron tungstide that had separated out of the meshes of solid solution surrounded by the rib-shaped eutectic. 


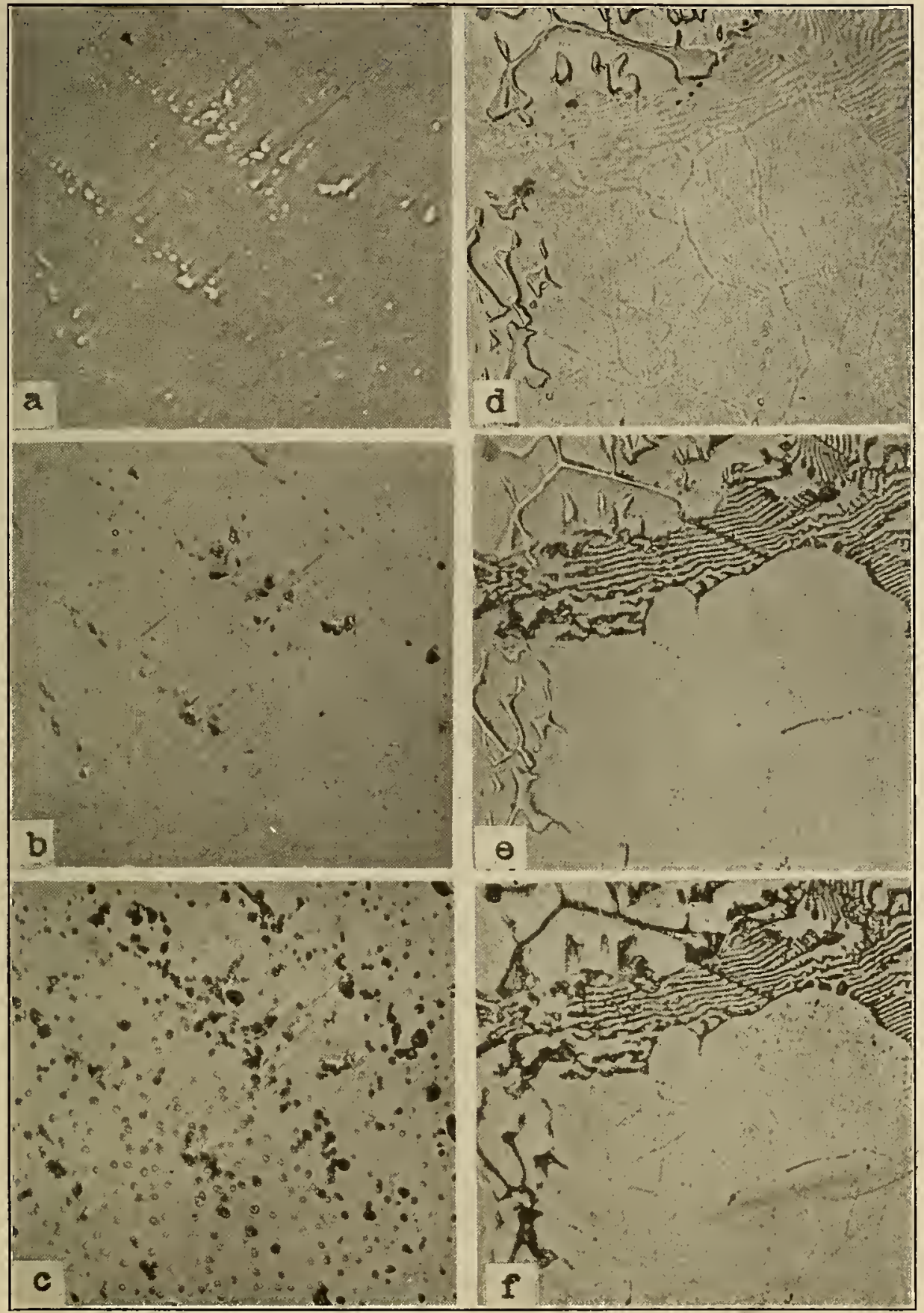

FIG. 13.-Microstructures of two low tungsten-high vanadium high-speed steel specimens. $\times 500$

The Jeft-hand series of micrographs is of a cutting tool (4i. Table 1; see footnote P), and the righthand series of a small piece of the same grade of steel (36; see footnote $\mathrm{P}$ ) which had heen fused in vacuo and cooled with the furnace. The presence of the "hard constituent" is clearly shown in the unetched section ( $a$ and $d$ ).

$b$ etched electrolytica!ly with 10 per cent sodium cyanide solution ("hard constituent" now darkened), $c$ and $e$ etched with 10 per cent $\mathrm{NaOH}$ solution- $\mathrm{H}_{2} \mathrm{O}_{2}$ mixture (Yatsevitch's reagent, the high-speed steel constituent is darkened while the "hard constituent" in $e$ remains undarkened), and $f$ with hot alkaline potassium permanganate solution (this darkens the "hard constituent ").

All micrographs in each series taken at the same spot in microsection, which was not repolished between the etchings. 


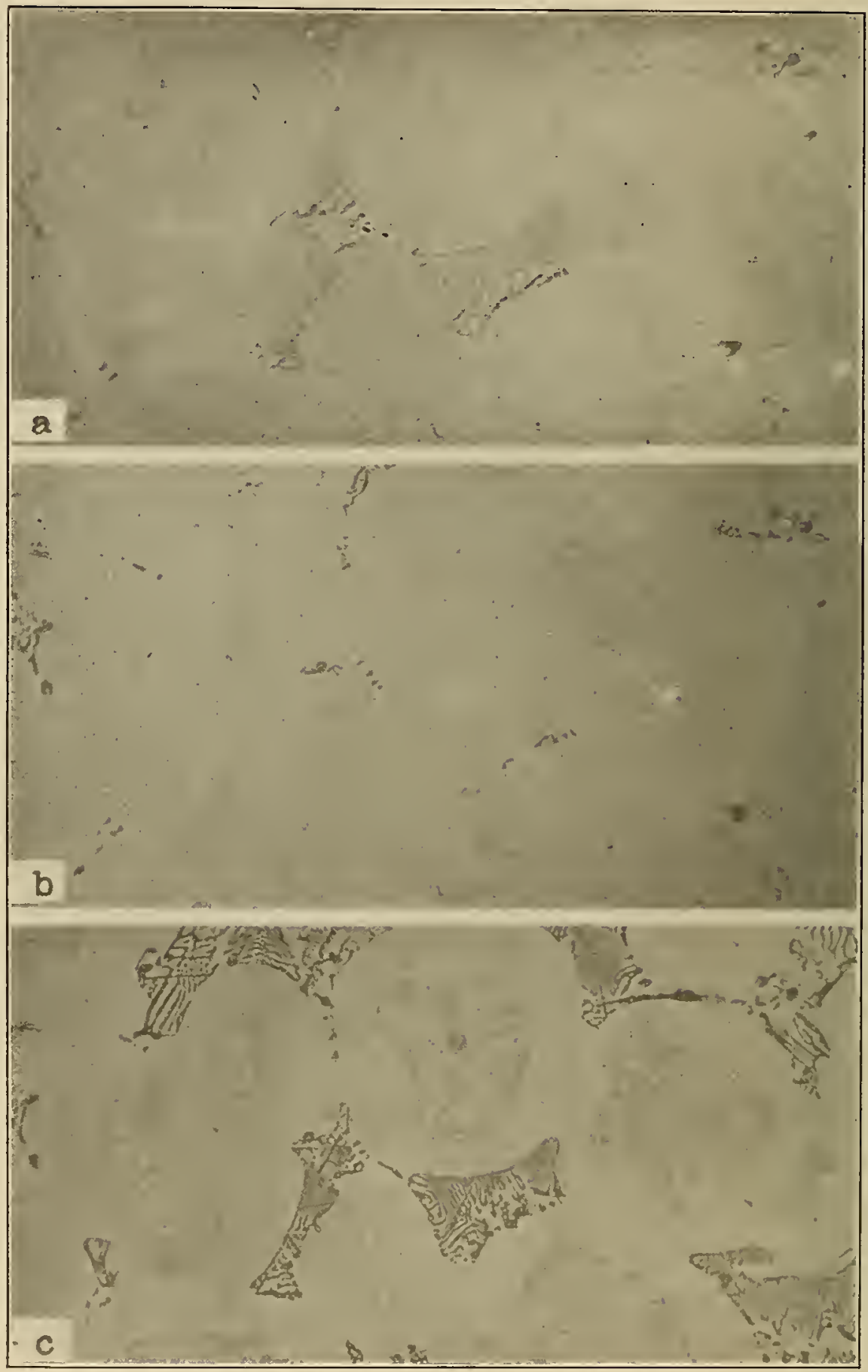

FIG. 11.-Microstructures of a high tungsten-low vanadium high-speed sted cutting tool bar $(3 \%$, Table 1). $\times 500$

This har had been heaterl to $\pm 2.450^{\circ} \mathrm{F}$. $\left(1,340^{\circ} \mathrm{C}\right.$ ) and (quenched (?) in oil; the cutting elge at one end of bar had partially fused and the bar was so fragile on being removed from the furnace that it broke into thice pieces. The presence of a hard, unidentified constituent and of the usual high-speed steel constituent (both in the eutectic and eutectoid forn for this particular specimen) has been clearly brought out by sequence etching.

$a$, not etched; $b$, etched electrolytically with 1 per cent NaOll solution (the "hard constituent" is now darkened), and c with 10 per cent $\mathrm{NaOll}-\mathrm{H}_{2} \mathrm{O}_{2}$ mixture (Yatseriteh's reagent).

All micrographs taken at same spot in microsection, which was not repolished hetween the etchings. 


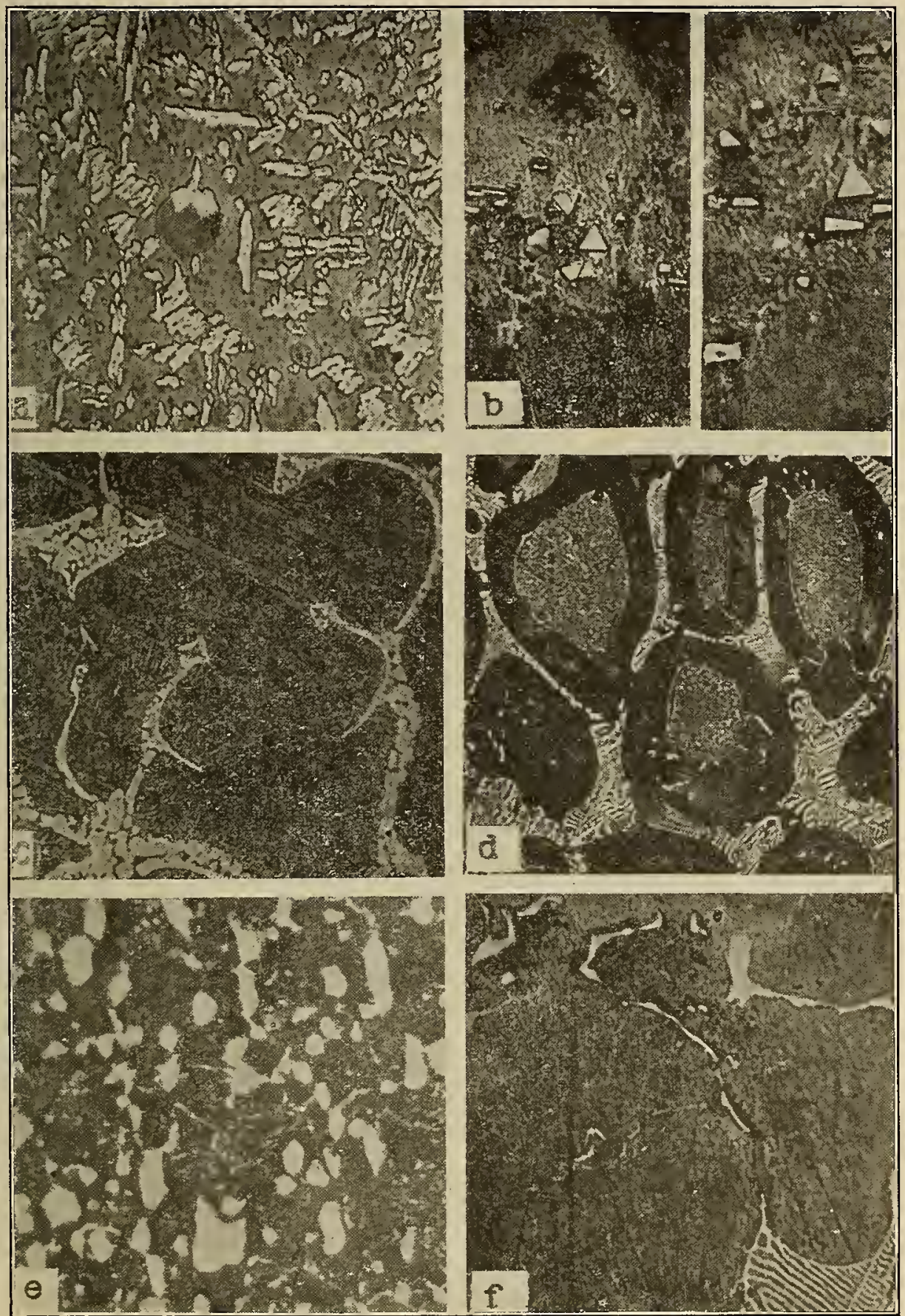

FiG. 15.-Microstructures of various steel specimens that had been heat-tinted (see Table 4, p. 566). $\times 500$

$a$, tungsten-iron alloy (25.5 per cent $\mathrm{W}$ and 005 per cent $\mathrm{C}, 34, \mathrm{C}$; Table 1 ).

$b$, tungsten steel ( 5.2 per cent $\mathrm{W}$ and 1.2 per cent $\mathrm{C}, 27, \mathrm{E})$.

$c$, high tungsten steel (11.7 per cent $W$ and 1.6 per cent $C, 31, \mathrm{I})$

$d$, high tungsten steel (23.6 per cent $W$ and 0.7 per cent $C, 32, I$ )

$c$, high tungsten-low vanadium high-speed steel $(41, \mathrm{E})$.

$f$, fused button of low tungsten-high vanadium high-speed steel (36)

NOTE.-The two micrographs shown in $b$ were taken at different spots in the same microsection. 


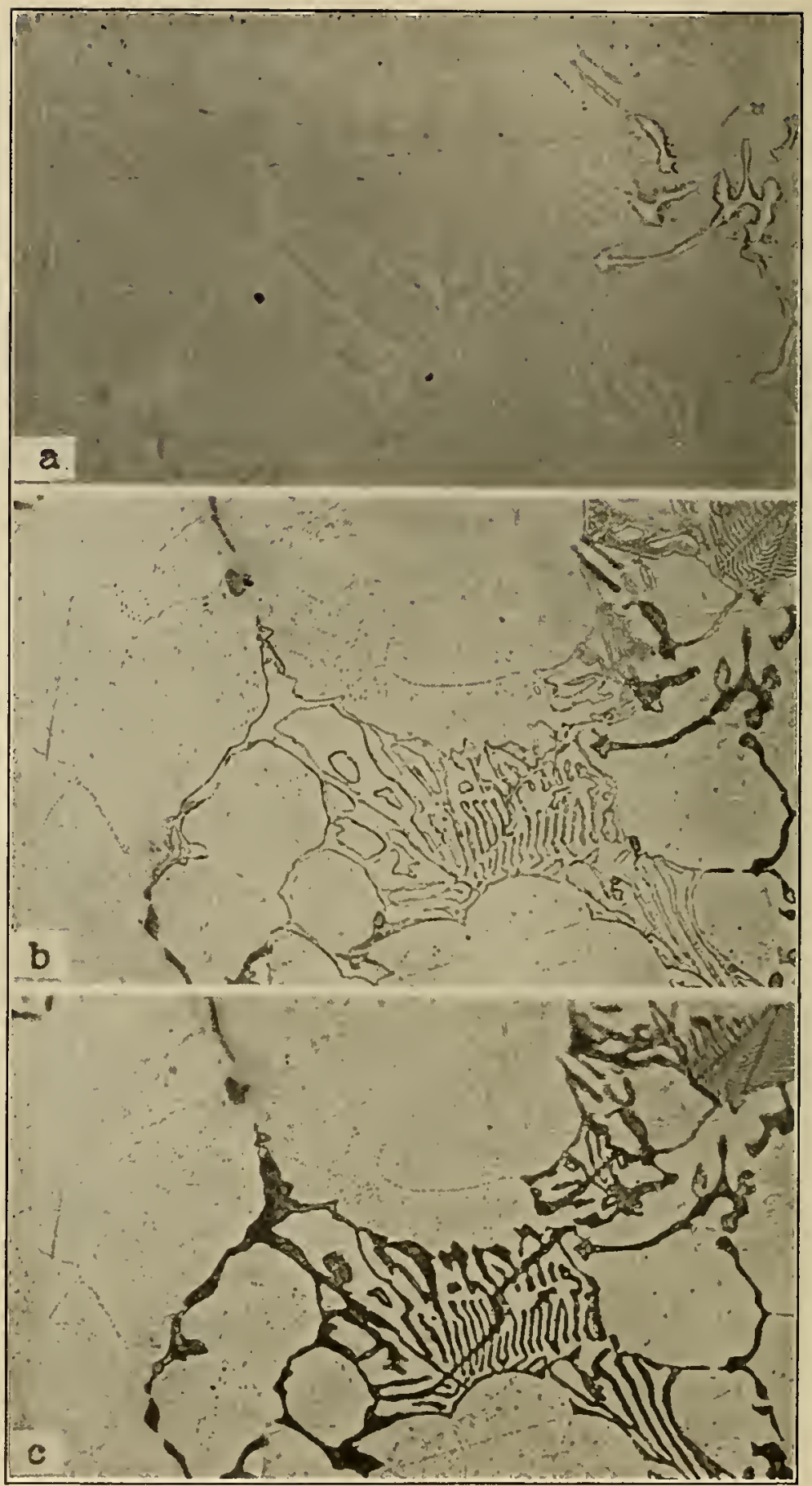

FIG. 16.- Microstructures of a low tungsten-high imnalium high-speed steel specimen thot had been fused in lucuo and cooled with furnace (\$6, Table 1). $\times 500$

This series of micrographs show, as revealed by the "sequence etching" methor, three different structurally free constituents which were found present in the microsection of the fused hutton.

$a$, unetched; $b$, etched electrolytically with 1 ner cent NaOH solution (the "hard constituent" is now darkened), c with 10 per cent $\mathrm{NaOH}-\mathrm{H}_{2} \mathrm{O}_{2}$ mixture (Yatsevitch's reagent. which darkens iron tungstide). 


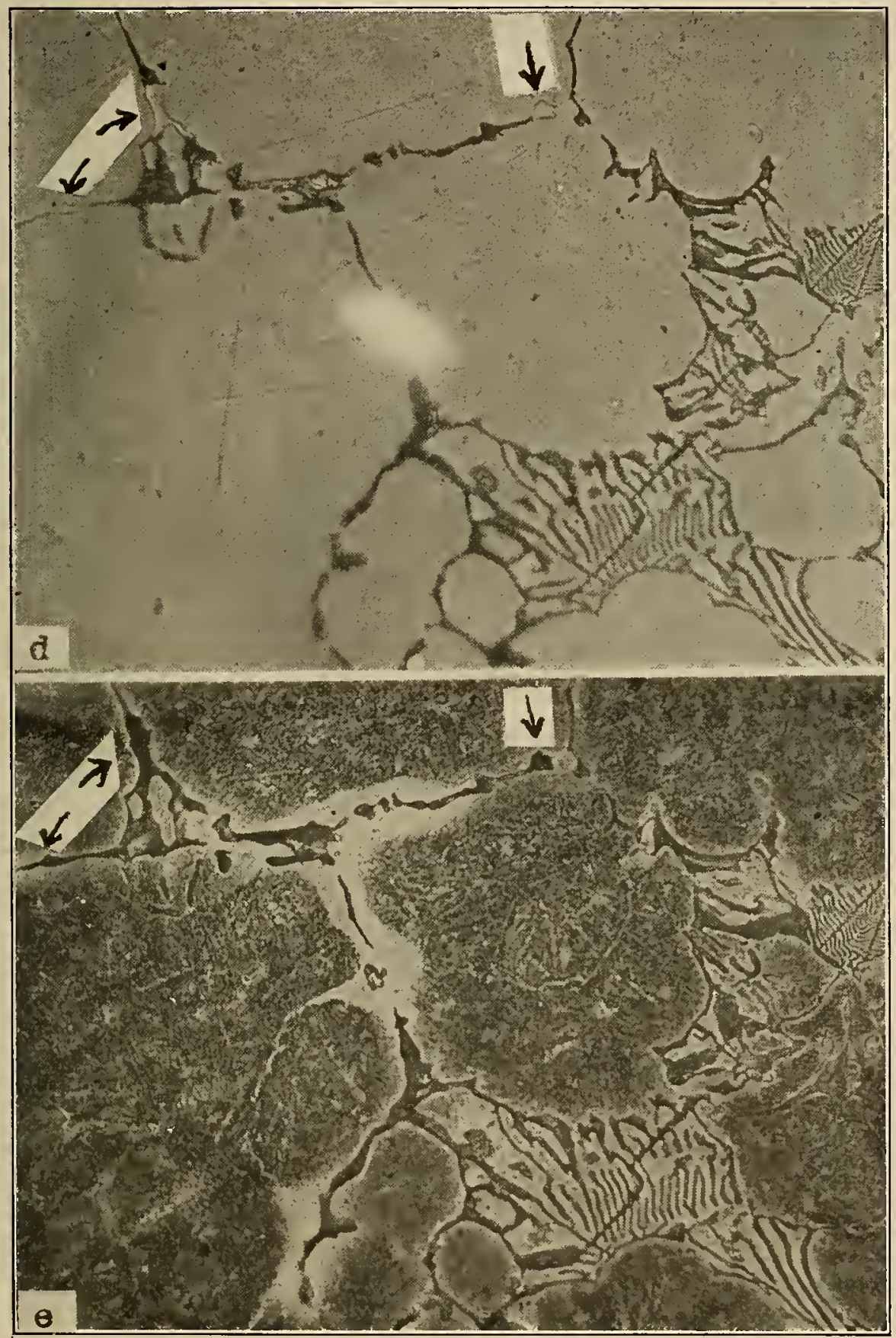

Fig. 16.-Continued

$d$, etched with 2 per cent alcoholic $11 \mathrm{NO}_{3}$ (to outline more sharply several particles of a constituent which remained undarkened during the jrevious etchings), and $e$ with hot alkalinc sodium picratc solution (Kourbatoff's reagent, the particles outlincd by the $\mathrm{HINO}_{3}$ etching have now been darkened, henec they appear to be cementite).

All micrographs were taken at same spot in microsection, although a portion of the ficld shown in $d$ and $e$ are not ineluded in $q, b$, and $c$. The microsection was not repolished between any of the etchings. (The white spot in $d$ is due to a defect in the photographic negative.) 


\section{SUMMARY AND CONCLUSIONS}

1. The objects of this investigation were the obtaining of experimental data on the behavior toward various etching solutions of constituents commonly occurring in alloy steels and ferro-alloys, such as iron, chromium, tungsten, and vanadium carbides, iron tungstide, and the complex constituent usually found in high-speed steels; the deducing from these data of the underlying principles which govern the behavior of these constituents to the various solutions; and the developing of methods for identifying one or more of these constituents that may be present in the steel or alloy.

2. Three etching methods--(a) etching by immersion, (b) electrolytic etching, and (c) heat-tinting-were employed in this study.

3. Etching with acidic solutions offers no means of distinguishing between any of these constituents. The use of alkaline reagents under oxidizing and nonoxidizing conditions furnishes, however, the desired differentiation between certain of these constituents.

4. With solutions containing an alkali, two distinct etching effects are obtained by immersion-(a) A chemical attack by the alkali directed solely to the constituent, and $(b)$ the oxidation of the constituent by nascent oxygen generated in the reaction between the alkali and certain salts in the solution. The resulting oxidized compound is generally "eaten out." The iron matrix remains bright in both trpes, apparently having been rendered passive by the alkali or nascent oxygen present. The constituents attacked in type $(a)$ were iron carbide, iron tungstide, and the high-speed steel constituent, and in type (b) all the constituents were affected.

5. In the electrolytic etching tests it was found that by using solutions of weakly dissociated acids and both alkaline and metallic salts of these acids the etching effect produced could be directed to the constituent while the iron matrix remained unattacked. With an arbitrarily adopted maximum time limit of three minutes for the etching period, the carbides of chromium, tungsten, and vanadium were, with a few exceptions, readily and similarly attacked, whereas iron carbide, iron tungstide, and high-speed steel constituent remained unaffected.

6. The explanation advanced for these two types of behavior shorn by the constituents is that oxygen is formed at the anode (specimen being etched) in two ways-(a) Through a secondary reaction occurring between the acid formed in the first stages of the electrolysis and water, and $(b)$ by the discharge of hydroxyl ions at the anode. The formation of oxygen in $(b)$ should occur to a greater extent with the use of alkaline salts of weakly dissociated acids, since the alkali product of the electrolysis is strongly dissociated and the acid dissociates to a much less extent. The particles of the constituents thus 
exposed to the oxygen are oxidized and more or less dissolved out, while the iron matrix is rendered passive and, therefore, remains unattacked. All the constituents are attacked when electrolytically etched in a solution of alkali.

7. The heat-tinting method offers no means of distinguishing the various constituents, excepting iron carbicle, from one another.

8. In general, it is possible to identify the different constituents listed in paragraph 1 from one another, excepting tungsten carbide from chromium carbicle, by a suitable selection of etching method and solution. The characteristic crystalline form of the tungsten carbide aids in its identification.

9. A brief review of the literature on the equilibrium diagrams of binary and ternary alloy systems formed by chromium, tungsten, vanadium, or molybdenum with iron or carbon, or both, and also on the nature of the constituents found present in alloy steels and ferroalloys containing one or more of these alloying eleinents is included.

The writer wishes to express his indebtedness to the following: H. S. Rawdon for helpful suggestions, L. Jordan and R. P. Neville (deceased) for preparing some of the alloys used in this investigation, H. J. French for the high-speed steel specimens, H. A. Bright for chemical analyses, and A. M. Bloxton for the preparation of the numerous specimens employed in the etching tests. 


\section{SELECTED BIBLIOGRAPHY}

1. Adcock, F., Electrolytic etching of metals, J. Inst. Metals, 26, p. 361; 1921.

2. Andrews, M. R., Production and characteristics of the carbide of tungsten, J. Phys. Chem. 27, p. 270; 1923. Also see J. Franklin Inst. 192, p. 545; 1921.

3. Andrews, M. R., and Dushman, S., Diffusion of carbon through tungsten and tungsten carbide, J. Phys. Chem., 29, p. 462; 1925.

4. Arnold, J. O., and Read, A. A., The chemical and mechanical relations of iron, chromium, and carbon, J. Iron Steel Iust., 83, p. 249; 1911.

5. Arnold, J. O., and Read, A. A., The chemical and mechanical relations of iron, tungsten, and carbon, Proc. Inst. Mech. Eng. (London), 1914, No. 2, p. 223 .

6. Arnold, J. O., and Read, A. A., The chemical and mechanical relations of iron, vanadium, and carbon, J. Iron Steel Inst., 85, p. 218; 1912.

7. Arnold, J. O., and Read, A. A., The chemical and mechanical relations of iron, molybdenum, and carbon, Proc. Inst. Mecl. Eng. (London), 1915, No. 2, p. 629.

8. Arnold, J. O., and Ibbotson, F., The molecular constitution of high-speed tool steels and their correlations with lathe efficiencies, J. Iron Steel Inst., 99, p. $407 ; 1919$.

9. Amold, J. O., The correlation of the chemical constitutions of "true steels" with their micrographic structures, J. Iron Stecl Inst. 107, p. 213; 1923.

10. Austin, C. R., Alloys in the ternary system iroll-chromium-carbon, J. Iron Steel Inst. 108, p. 235; 1923.

11. Bain, E. C., and Jeffries, Z., Cause of red hardness of high-speed steel. Iron Age, 112, p. 205; 1923.

12. Bornemann, K., Die-binären metallegierungen. (Fe-Cr). Metallurgie, 9, p. $346 ; 1912$.

13. Czochralski, J., Hauparten der aetzerscheinungen und die metallographischen aetzverfahren, Stahl u. Eiscn, 35, pp. 1073, 1129; 1915.

14. Daeves, K., Grenzen des loslichkeit für Kohlenstoff in ternären stählen I. System Cr-Fe-C; II. System IV-Fe-C. Z. anorg. allegem. Chem. 118, p. $55 ; 1921$.

15. Daeves, K., Ein neues aetmittel für chrom und wolfram-Stähle. Stahl ı. Eisen, 36, p. 1262; 1921.

16. Edwards, C. A., Sutton, H., and Oishi, G., Properties of iron-chromiumcarbon steels. J. Iron Steel Inst. 101, p. 403; 1920.

17. Edwards, C. A., Function of chromium and tungsten in high-speed tool steel, J. Iron Steel Inst. 77, p. 104; 1908.

18. Fetiveiss, F., Mikroskopische untersuchung ciniger hochlegierten sonderstähle, Stahl u. Eisen, 32, p. 1866; 1912.

19. Fischbeck, K., Ueber das dreistoff-schaubild der Fc-Cr-C legiergungen. Stahl u. Eisen, 44, p. 715; 1924.

20. Giesen, W., The special steels in theory and practice. Iron Steel Inst. (London), Carnegie Schol. Mem. 1, p. 1; 1909.

21. Gill, J. P., and Bowman, L. D., The metallography of high-specd steel, Trans. Am. Soc. Steel Trcating, 2, p. 184; 1921. 
22. Goerens, P., and Stadeler, A., Über den einfluss des chroms auf die lösungsfahigkeit des eisens für kohlenstoff und die graphitbild`ıng. Metallurgie, 4, p. $23 ; 1907$.

23. Grossman, M. A., and Bain, E. C., On the nature of high-speed steel, J. Iron Steel Inst. 110, p. 249; 1924.

24. Guertler, W., Die ätzmittel des metallographen. Intern. Z. Metallog., 8, p. 228; 1916; and Z. Metallkunde, 12, p. 44; 1920.

25. Guertler, W., Metallographie, I Band, I Teil, p. 370, Gebrüder Borntraeger, Berlin; 1912.

26. Guillet, L., Etude industrielle des alliages metalliques, Dunod ct Pinat, Paris; 1906.

27. Guillet, L., Les aeiers an ehrome, Rev. métal, 1, p. 155; 1904.

28. Harkort, H., Beitrag zum studium des systems eisen-wolfram. Metallurgie, 4, p. $617 ; 1907$.

29. Hilpert, S. and Ornstein, M., A simple preparation of molybdenum and tungsten carbides, Ber., 46, p. 1669; 1913.

30. Hilpert, S., and Colver-Glauert, E., Sulphurous aeid as a metallographie etehing medium, J. Iron Steel Inst. 82, p. 54; 1910.

31. Honda, K., and Murakami, T., On the strueture of tungsten steel and its change under heat treatment, Sei. Repts. Tôhoku Imp. Univ., 6, p. 235; 1918; Rev. métal., 17, p. 37; 1920; Chem. Met. Eng., 24, p. 745; 1921.

32. Honda, K., and Murakami, T., Struetural constitution of high-speed steel containing chromium and tungsten and the effeet of these elements on its hardening and tempering, Sei. Repts. Tôhoku Imp. Univ., 9, 143; 1920; J. Iron Steel Inst. 101, p. 647; 1920; Chem. Met. Eng. 24, p. 791; 1921.

33. Honda, K., and Murakami, T., On the strueture of the magnet steel and its change with the heat treatments, Sci. Repts. Tôhoku Imp. Univ., 6, p. $53 ; 1917$.

34. Hudson, O. F., Etching reagents and their applications, J. Inst. Metals, 13, p. $193 ; 1915$.

35. Hultgren, A., A metallographie study on tungsten steels, J. Wiley \& Sons, New York; 1920.

36. Ishiwara, I., On the magnetic analysis of earbides found in different kinds of steel, Sci. Repts. Tôhoku Imp. Univ., 6, p. 285; 1918.

37. Jänecke, E., Úber die konstitution der eisen-ehromlegierungen. Z. Elektrochem, 23, p. 49; 1917.

38. Jeffries, Z., Metallography of tungsten, Trans. Am. Inst. Mining Met. Eng., 60, p. 1917; 1919; idem, 56, p. 600; 1916.

39. Lautsch and Tammann, G., Über die legiergungen des eisens mit molybdün, Z. anorg. Chem., 55, p. $386 ; 1907$.

40. Lohmann, H., Ueber lohe temperaturen, Elektrochem. Z., 26, p. 29; abstract in Chem. Met. Eng., 25, p. 120; 1921. Method of produeing tungsten carbice in electrie furnace.

41. Loskiewicz, L., Une étude sur le tomps d'attaque aux reaetifs micrographiques des alliages fer-carbone, Rev. métal., 19, p. 681; 1922.

42. Monnartz. Dissertation, Aachen., 1911 (through Fisehbeek, referenee No. 19).

43. Monypenny, J. H. S., The strueture of some ehromiun steels, J. Iron Steel Inst., 101, p. 493; 1920.

44. Murakami, T., On the strueture of iron-chromium-earbon alloys. Sci. Repts. Tôhoku Imp. Univ., 1, p. 217; 1918; J. Iron Steel Inst., 100, p. $447 ; 1919$.

45. Norris, G. L., Properties of vanadium steels, Proe. Am. Soe. Testing Materials, 17, pp. 20, 47; 1917. 
46. Oberhoffer, P., and Daeves, K., Beitrag zur kenntnis der sogenannten doppelkarbidlıaltigen chrom- und wolframstälıle. Stahl u. Eisen, 40, p. 1515; 1920.

47. Oberhoffer, P., Ueber den einfluss der erstarrungs-geschwindigkeit auf die doppel-karbidstähle. Stahl u. Eisen, 42, p. 1240; 1922.

48. Oberhoffer, P., Daeves, K., and Rapatz, F., Nachprüfung der loslichkeitslinie für kollenstoff in chrom und wolframstählen, Stahl u. Eisen, 44, p. 432; 1924; iden, 45, p. 583; 1925.

49. Oertel, W., and Pakulla, E., Beitrag zur frage der kobalt-chrom-wolfram(molybdän-) legiergungen, Stahl 11. Eisen, 44, p. 1717; 1924.

50. Ozawa, S., On the constitutional diagram of the iron-carbon-tungsten diagram. Sci. Repts. Tôhoku Imp. Univ., 11, p. 333; 1922.

51. Pilling, N. B., Micrographic detection of carbides in ferrous alloys. Trans. Am. Inst. Mining Met. Eng., 70, p. 254; 1924.

52. Portevin, A. M., On constituents fonnd in tungsten and molybdenum steels, J. Iron Steel Inst., 104, p. 141; 1921.

53. Rawdon, H. S., Use of ammonium persulphate for revealing the macrostructure of iron and steel, B. S. Sci. Paper No. 402; 1920.

54. Robin, F., Traité de metallographie, A. Herman et Fils, Paris, 1912, p. 46.

55. Ruff, O., and Foehr, T., Chrom und kohlenstoff, Z. anorg. Chem., 104, p. $27 ; 1918$.

56. Ruff, O., and Wunsch, R., Wolfrain und kollenstoff, Z. anorg. Chem., 85, p. $292 ; 1914$.

57. Russell, T. F., On the constitution of chromium steels, J. Iron Steel Inst., 104, p. 247; 1921.

58. Sauveur, A., and Krivobok, V. N., Use of sodium picrate in revealing dendritic segration in iron alloys, Trans. Am. Inst. Mining Met. Eng., 70, p. 239; 1924.

59. Swinden, T., Carbon-tungsten steels, J. Iron Steel Inst., 73, p. 291; 1907. The constitution of carbon-tungsten steels, iden, 80, p. 223; 1909.

60. Swinden, T., Carbon-molybdenum steels, Iron Steel Inst. (London), Carnegie Schol. Mem., 3, p. 66; 1911. A study of the constitution of carbonmolybdenum steels, idem, 5, p. 100; 1913.

61. Thompson, F. C., and Whitehead, E., Some notes on the etching properties of the alpha and beta forms of tricarbide of iron. Trans. Faraday Soc., 19, p. 152; 1923.

62. Treitschke, W., and Tammann, G., Über die legiergungen des eisens mit chrom. Z. anorg. Chemie, 55, p. 402; 1907.

63. Vogel, R., and Tammanı, G., UUber vanadin-eisenlegierungen. Z. anorg. Clem., 58, p. 73; 1908.

64. Weitzenkorn, J. W., Notes on the manufacture of high-speed and tungsten steels, Chem. Met. Eng., 26, p. 504; 1922.

65. Westgren, A., and Phragmén, G., On the structure of solid solutions, Nature, 113 , p. $122 ; 1924$.

66. Wever, F., Beiträge zur Kenntnis des eisenkarbides. Mitt. Kaiser-Wilhelm Inst. Eisenforschung zu Düsseldorf, 4, p. 67; 1922.

67. White, A. E., Carbide segregation in high-speed steel. Trans. Am. Soc. Steel Treating, 3, p. 386; 1923.

68. Yatsevitch, M., Recherches sur l'acier a coupe rapide. Rev. métal, 15, p. 65; 1918.

Washington, May 18, 1925. 